\title{
Resistance of the Wheat Cultivar 'Renan' to Septoria Leaf Blotch Explained by a Combination of Strain Specific and Strain Non-Specific QTL Mapped on an Ultra-Dense Genetic Map
}

\author{
Camilla Langlands-Perry ${ }^{1,2}$, Murielle Cuenin ${ }^{1}$, Christophe Bergez $^{1}$, Safa Ben Krima ${ }^{1}$, Sandrine Gélisse ${ }^{1}$, \\ Pierre Sourdille $^{3}$ (D), Romain Valade ${ }^{2}$ id and Thierry C. Marcel ${ }^{1, *(D)}$
}

check for updates

Citation: Langlands-Perry, C.; Cuenin, M.; Bergez, C.; Krima, S.B.; Gélisse, S.; Sourdille, P.; Valade, R.; Marcel, T.C. Resistance of the Wheat Cultivar 'Renan' to Septoria Leaf Blotch Explained by a Combination of Strain Specific and Strain Non-Specific QTL Mapped on an Ultra-Dense Genetic Map. Genes 2022, 13, 100. https://doi.org/10.3390/ genes13010100

Academic Editors: Anna

M. Mastrangelo and

Elisabetta Mazzucotelli

Received: 3 December 2021

Accepted: 22 December 2021

Published: 31 December 2021

Publisher's Note: MDPI stays neutral with regard to jurisdictional claims in published maps and institutional affiliations.

Copyright: (C) 2021 by the authors. Licensee MDPI, Basel, Switzerland. This article is an open access article distributed under the terms and conditions of the Creative Commons Attribution (CC BY) license (https:// creativecommons.org/licenses/by/ $4.0 /)$.
1 Université Paris Saclay, INRAE, UR BIOGER, 78850 Thiverval-Grignon, France; Camilla.Langlands-Perry@inrae.fr (C.L.-P.); murielle.cuenin@gmail.com (M.C.); christophe.bergez@free.fr (C.B.); safabenkrimapro@gmail.com (S.B.K.); sandrine.gelisse@inrae.fr (S.G.)

2 ARVALIS Institut du Végétal, 91720 Boigneville, France; R.VALADE@arvalis.fr

3 Université Clermont-Auvergne, INRAE, UMR GDEC, 63000 Clermont-Ferrand, France; pierre.sourdille@inrae.fr

* Correspondence: thierry.marcel@inrae.fr
Abstract: Quantitative resistance is considered more durable than qualitative resistance as it does not involve major resistance genes that can be easily overcome by pathogen populations, but rather a combination of genes with a lower individual effect. This durability means that quantitative resistance could be an interesting tool for breeding crops that would not systematically require phytosanitary products. Quantitative resistance has yet to reveal all of its intricacies. Here, we delve into the case of the wheat/Septoria tritici blotch (STB) pathosystem. Using a population resulting from a cross between French cultivar Renan, generally resistant to STB, and Chinese Spring, a cultivar susceptible to the disease, we built an ultra-dense genetic map that carries 148,820 single nucleotide polymorphism (SNP) markers. Phenotyping the interaction was done with two different Zymoseptoria tritici strains with contrasted pathogenicities on Renan. A linkage analysis led to the detection of three quantitative trait loci (QTL) related to resistance in Renan. These QTL, on chromosomes 7B, 1D, and 5D, present with an interesting diversity as that on 7B was detected with both fungal strains, while those on $1 \mathrm{D}$ and $5 \mathrm{D}$ were strain-specific. The resistance on $7 \mathrm{~B}$ was located in the region of $S t b 8$ and the resistance on $1 \mathrm{D}$ colocalized with $S t b 19$. However, the resistance on 5D was new, so further designated Stb20q. Several wall-associated kinases (WAK), nucleotide-binding and leucine-rich repeats (NB-LRR) type, and kinase domain carrying genes were present in the QTL regions, and some of them were expressed during the infection. These results advocate for a role of $S t b$ genes in quantitative resistance and for resistance in the wheat/STB pathosystem being as a whole quantitative and polygenic.

Keywords: bread wheat; Septoria tritici blotch; quantitative trait loci; Stb20q; strain specificity; resistance durability

\section{Introduction}

Bread wheat (Triticum aestivum) is a staple food in many countries worldwide and is an economically important crop. Septoria tritici blotch (STB) is the most common disease of wheat and is caused by the ascomycete fungus Zymoseptoria tritici (formerly Mycosphaerella graminicola). It is responsible for high yield losses worldwide, ranging from 30 to $50 \%$ loss when environmental conditions are favourable to the disease's development [1,2]. Disease control is generally undertaken with the application of fungicide treatments and/or cultivation of varieties carrying major resistance $(R)$ genes. Neither of these methods, nor indeed their combination, are considered to be durable, thus necessitating constant renewal and research. Indeed, with ever-increasing restrictions on the use of 
chemical treatments in crops, a fully chemical approach does not seem to be the way to go. Another factor which encourages reducing the use of chemical treatments for this disease is their cost, which comes to more than 400 million euros a year in Europe [3]. $R$ genes and their pyramiding appear as an excellent alternative. However, due to the existence of a gene-for-gene interaction between $R$ genes and Avr avirulence genes in the fungus, the former are often overcome. Indeed, a single mutation in the Avr gene sequence can suppress recognition by the plant, stopping resistance mechanisms' action [4]. Quantitative resistance is considered to be polygenic and to have a smaller effect than that due to $R$ genes. It therefore imposes less selection pressure on fungal populations, making it more durable. Very few quantitative trait loci (QTL) or quantitative genes for resistance have been cloned, and the few that have are varied in terms of gene families and underlying mechanisms with cases of specificity and non-specificity [4-14]. The T. aestivum-Z. tritici pathosystem is considered to be primarily quantitative, though 22 major resistance genes in bread wheat have been described [15], the most recent being Stb19 [16]. In controlled conditions as in the field, resistance to STB manifests itself as being quantitative, largely additive and with varying heritability. Brown et al. (2015) [15] counted 89 STB resistance QTL carrying regions, for a total of 167 individual QTL. Among these 89 regions are 62 QTL and 27 meta-QTL. Brown et al. (2015) [15] describe QTL as showing lower plant stage specificity than major resistance genes. These were not all detected at the same developmental stage, 27 at a seedling stage, 48 in adult plants and 14 for both of these stages. These regions are located on all wheat chromosomes but chromosome 5D, while chromosomes $3 \mathrm{~B}, 6 \mathrm{~B}$, and $7 \mathrm{~B}$ are more represented than others [15]. Moreover, several recent studies have reported additional QTL for resistance to STB [17-22], with $\mathrm{r}^{2}$ values ranging from $3.3 \%$ to 29.52\%. Notably, Vagndorf et al. (2017) [17] detected QTL on chromosomes 1B, 2A, 5D, and 7A, with the QTL on chromosome 5D being the most effective of all four. These different studies show that STB resistance in wheat is complex, due to the combination of a large number of QTL with varying effects on phenotypes. No STB quantitative resistance genes have been cloned. However, major resistance gene $S t b 6$ was the first cloned gene specifying resistance to STB [23]. It encodes a wall-associated kinase-like protein, which detects the presence of a matching apoplastic effector. A second major resistance gene Stb16q was cloned in 2021, which confers broad-spectrum resistance against Z. tritici and encodes a cysteine-rich receptor-like kinase [24]. There is a gene-for-gene relationship between Stb6 and AvrStb6 [25], which is the avirulence gene which encodes a small secreted protein, the aforementioned apoplastic effector. This relationship entails specificity between cultivars carrying Stb6 and strains carrying AvrStb6. Created in 1989 by INRA Rennes, Renan is a four-way hybrid resulting from a complex cross between cultivars Courtot, VPMxMoisson, Maris Huntsman, and Mironovskaia-808 (Doré and Varoquaux, 2006) [26]. Renan has the advantage of having very good baking quality and a high tolerance to the cold. Renan is resistant to a number of diseases such as cereal rusts, eyespot, septoria leaf blotch, and fusarium. These resistances result in part from the introgression of two chromosomal fragments from Aegilops ventricosa which carry the resistance gene to eyespot Pch1, on chromosome 7D, and resistance genes to rusts Lr37, Yr17, and Sr38 [27-29] on chromosome 2A. Until the end of the 1990s, Renan had a good level of resistance to septoria leaf blotch. However, this resistance has been overcome by certain strains, even if Renan's global disease resistance level remains reasonably good. Due to its disease resistance qualities, relative shortness and reasonably good competitive value against weeds, Renan is a popular choice for organic farming [30]. Chinese Spring is the reference genome for wheat and has been used in a great number of studies [31]. It was the first wheat to have its genome fully sequenced and assembled [32,33], and that sequence remains the most contiguous wheat assembly to date [34]. Moreover, it is sensitive to a wide array of biotic and abiotic stresses, including STB. This means that it is ideal as a sensitive parent for a bi-parental population with a resistant parent such as Renan [35]. One thing to bear in mind when working with Chinese Spring is that it carries resistance gene $S t b 6$ and is therefore resistant to isolates carrying the corresponding avirulence gene AvrStb6 [25]. The aim of this study is to better under- 
stand quantitative resistance to STB and the isolate-specificities of QTL. We hypothesize that these specificities could be due to minor gene-for-minor gene interactions, such as those that have already been suggested in other works, in the cases of barley-barley leaf rust [36,37], barley—barley leaf stripe [38], potato-Phytophthora infestans [39] or indeed pepper and potyviruses [40]. Further knowledge of these interactions would give us better understanding of the durability of quantitative resistance.

\section{Materials and Methods}

\subsection{Plant and Fungal Materials}

The plant material used in this study consisted in a population of 236 Recombinant Inbred Lines (RILs; F6 generation) obtained from a cross between wheat cultivars Renan and Chinese Spring. Hereafter, this population will be referred to as RxCS. The fungal strains used in this study are INRA09-FS0813 and INRA09-FS0732, which we will refer to hereafter as I05 and I07, respectively. These two strains were isolated from leaves of the cultivar Soissons collected from the same field in 2009 at Thiverval-Grignon in France. They are both virulent on Stb6. They were chosen for this study out of a panel of eight different strains as they were both pathogenic on Chinese Spring and showed contrasted pathogenicity on Renan. I05 can infect Renan, while I07 cannot.

\subsection{Experimental Setup and Procedure for Pathology Assays}

\subsubsection{Data Sets}

Due to the size of the population, it could not be phenotyped in its entirety over one experiment. It was therefore divided into two equal sets, which were tested in 2017 with two replications. All phenotypic traits were evaluated for this set. To corroborate results, 148 individuals were chosen randomly out of the original 236, and tested over three replications in 2018. For this data set, PYC and NBS (explained later on) were not evaluated. For every experiment, Renan and Chinese Spring were used as controls.

\subsubsection{Culture Conditions}

For each individual in the population, five seeds were sown per pot filled with Floradur B (Floradur Pot Medium) potting soil (NPK 14, 16, $18 \mathrm{~kg} \cdot \mathrm{m}^{-3}$ ) (Floragard Vertriebs-GmbH, Oldenburg, Germany). The pots were split into trays with 15 pots per tray, for a total of 8 trays per experiment. Before inoculation, plants were cultivated in a climate chamber with a $16 \mathrm{~h}$ photoperiod, hygrometry fixed at $70 \%$ and temperatures at $16{ }^{\circ} \mathrm{C}$ night and $20{ }^{\circ} \mathrm{C}$ day. Post-inoculation, plants were placed in a climate chamber with a $16 \mathrm{~h}$ photoperiod, hygrometry fixed at $90 \%$ by day, $80 \%$ by night and temperatures of $22{ }^{\circ} \mathrm{C}$ during daytime and $18{ }^{\circ} \mathrm{C}$ at night-time. In the climate chambers, light conditions were maintained at $300 \mu \mathrm{mol} \cdot \mathrm{m}^{-2} \cdot \mathrm{s}^{-1}$ with eight neon tubes (Osram Lumilux L58W/830 placed $40 \mathrm{~cm}$ above the trays (OSRAM GmbH, Munich, Germany).

\subsubsection{Inoculum Preparation}

Inocula were prepared from strains conserved at $-80{ }^{\circ} \mathrm{C}$ as spores in a $70 \%$ water and $30 \%$ glycerol mix. The strains are precultured 10 days prior to inoculation in $10 \mathrm{~mL}$ of a YPD liquid culture medium (1\% yeast, $2 \%$ bacto-peptone, $2 \%$ glucose). The precultures were kept in a growth chamber for 6 days at $17{ }^{\circ} \mathrm{C}$ and a hygrometry of $70 \%$ under agitation (140 rpm). Each preculture was then grown in a petri dish (Ø 90) on a PDA (potato dextrose agar) solid culture medium with 50 to $80 \mu \mathrm{L}$ of inoculum. The day of the inoculation, $150 \mathrm{~mL}$ of inoculum were prepared from these cultures, each with a concentration of $1.106 \pm 0.1 .106$ spores $\cdot \mathrm{mL}^{-1}$. Lastly, one drop of Tween 20 was added per $15 \mathrm{~mL}$ of inoculum to insure adherence of the inoculum to the leaf surface.

\subsubsection{Inoculation}

Plants were inoculated 16 days after sowing. The day before the inoculation, only three plants out of a maximum of five were kept per pot. On the first true leaf (generally 3 to $5 \mathrm{~cm}$ 
from the base) of each plant, a surface of $7.5 \mathrm{~cm}$ in length was marked out with two black felt tip lines. The inoculum was spread out on this surface using a square-tipped flat paintbrush in six passages ( 3 times back and forth). Once all the pots of a tray were inoculated, the procedure was carried out a second time. The paintbrush was dipped into the inoculum before each set of six passages. After inoculation, each tray was watered and covered with transparent polyethylene bags. The bags create a water-saturated atmosphere, which encourages infection [41,42]. The bags were removed after three days, a $72 \mathrm{~h}$ incubation period being the time it takes for the fungus to reach the mesophyll, which is necessary to the rest of the colonisation process [43]. To optimise conditions for the survival of the inoculated leaf and to homogenise the quantity of light received by each leaf, new leaves were cut 2 to $3 \mathrm{~cm}$ above the first node 10 days post-inoculation (dpi).

\subsection{Evaluation of Phenotypic Traits}

\subsubsection{Visual Evaluation of Symptoms}

The leaf area marked out with black felt tip was visually evaluated at 14, 20, and $26 \mathrm{dpi}$. The percentage of the surface which was green, necrotic, and sporulating was evaluated. The sporulating area is defined here as the area which presents pycnidia, regardless of density, colour, or size. The values for sporulating area at 14, 20, and $26 \mathrm{dpi}$ were used as phenotypic traits in linkage analyses and are referred to as S14, S20 and S26. The chlorotic area was not evaluated because it is deductible from the green and necrotic areas. These notations were used to calculate AUDPCs (Area Under the Disease Progress Curve) for the green, necrotic, and sporulating areas (AUDPCG, AUDPCN, and AUDPCS, respectively) [44]. The formula for calculating an AUDPC is as follows:

$$
\mathrm{AUDPC}=\frac{\sum\left[\left(t_{i+1}-t_{i}\right) \times\left(y_{i}+y_{i+1}\right)\right]}{2}
$$

With:

$t_{i+1}-t_{i}$ : number of days between two notations (6 days)

$y_{i}$ : percentage of green, necrotic, or sporulating area at day $i$ (for AUDPCG, AUDPCN and AUDPCS respectively)

$y_{i+1}$ : percentage of green, necrotic, or sporulating area at day $i+1$ (for AUDPCG, AUDPCN and AUDPCS respectively).

\subsubsection{Pycnidia Counting by Image Analysis}

The procedure followed and macros used were developed by Stewart and McDonald (2014) [45] and improved by Stewart et al. (2016) [46]. Images were obtained by scanning the inoculated part of the leaf. Firstly, for sample identification, A4 pages are generated using a Linux supported macro. The page is divided into eight sections, each carrying a QR code which is specific to a sample. For each sample the three leaves are glued inside the corresponding section. Pages are then scanned using a CanoScan 9000F MarkII scanner (resolution $=1200 \mathrm{dpi}$, luminosity $=$ contrast $=0$ ) and the resulting images are saved as .tiff files. Pycnidia density was evaluated using a macro in ImageJ [47]. This macro is able to quantify several traits which are the percentage of the leaf surface covered by lesions or by necrosis only (PLACL or PLACN respectively), the total number of pycnidia per sample, the size of the pycnidia and the grey value of the pycnidia. For this study, only the total number of pycnidia per sample was taken into account (one sample being the three inoculated leaves for each strain). Parameters within ImageJ were adjusted for each image as it was not possible to use the exact same parameters for each sample, depending on the colours of the leaves.

Pycnidia density was calculated for each sample using the following formula:

$$
\text { PYC }=\frac{n_{\text {pycnidia total }}}{N_{\text {total }}}
$$

With: 
$n_{\text {pycnidia total }}$ : total number of pycnidia in the sample.

$N_{\text {total }}$ : total necrotic surface of the sample.

\subsubsection{Quantification of Sporulation}

Sporulation was quantified with the use of the particle size \& shape analyser Occhio Flowcell FC200S+HR (Occhio s.a., Angleur, Belgium). This tool is controlled by a computer which, with the help of image analysis, can precisely count particles while evaluating their size and shape. It is used alongside the Callisto software which controls the quality of the analysis. The user interface allows one to control various parameters such as light, image resolution and particle selection settings (Table 1). The latter is particularly important as it means that any particle that is not a pycnidiospore can be excluded from the analysis. Preparation of the samples for analysis is done the day after the last visual notation ( $27 \mathrm{dpi}$ ). The inoculated area of the leaf is cut out. The three leaves from each genotype are placed into a $15 \mathrm{~mL}$ Falcon tube containing $0.75 \mathrm{~mL}$ of osmosed water and two pieces of blotting paper $(10.5 \mathrm{~cm} \times 0.5 \mathrm{~cm})$. The blotting paper maintains a water-saturated atmosphere within the tube which favours the extrusion of cyrrhi from pycnidia, and thus sporulation [48]. Tubes are then placed in a growth chamber for at least $18 \mathrm{~h}$. On the next day, $5 \mathrm{~mL}$ of an $80 \%$ water $20 \%$ glycerol mix is added to each tube. The tubes are then gently agitated so that the spores present on the surface of the leaves are transferred to the liquid phase. The leaves are then removed from the tubes and mounted on a white paper sheet for scanning. The tubes containing pycnidiospores suspended in $5.75 \mathrm{~mL}$ water/glycerol are kept at $-20{ }^{\circ} \mathrm{C}$ awaiting analysis. Before the analysis, each tube is homogenized after the addition of a drop of Tween 20 to the mix. $0.9 \mathrm{~mL}$ of the mix are used for each analysis. As each sample is passed through the particle counter, an image control is used to verify that all particles are counted independently. Over 350,000 particles $\mathrm{mL}^{-1}$, the initial mix is too concentrated in particles thus it becomes necessary to dilute the sample and repeat the procedure. The particle counter is rinsed with osmosed water between each sample.

Table 1. Settings for the Occhio Flowcell FC200S+HR.

\begin{tabular}{|c|c|c|}
\hline \multirow{3}{*}{ Particle Counter } & Diameter & $0-8 \mu \mathrm{m}$ \\
\hline & Size & $7-85 \mu \mathrm{m}$ \\
\hline & Circonference & $0-0.70 \mu \mathrm{m}$ \\
\hline \multicolumn{2}{|c|}{ Grey value } & 195-205 \\
\hline \multicolumn{2}{|c|}{ Luminous intensity } & 7.5 \\
\hline \multicolumn{2}{|c|}{ Spacer thickness } & $150 \mu \mathrm{m}$ \\
\hline \multirow{2}{*}{ Resolution } & Magnification & $\times 4$ \\
\hline & Calibration & $0.47 \mu \mathrm{m}$. pixel $-1(1$ pixel $=1.67 \mu \mathrm{m})$ \\
\hline
\end{tabular}

For each sample, the total number of pycnidiospores was extracted from data obtained from this particle counter. The total number of pycnidiospores was used to calculate the number of pycnidiospores per pycnidium after image analysis.

The number of pycnidiospores per pycnidium (NBS) was calculated using the formula:

$$
\mathrm{NBS}=\frac{n_{\text {pycnidiospores total }}}{n_{\text {pycnidia total }}}
$$

With:

$n_{\text {pycnidiospores total }}$ : total number of pycnidiospores extracted from the sample

$n_{\text {pycnidia total }}$ total number of pycnidia in the sample. 


\subsection{Statistical Analysis of Phenotypic Data}

The obtained data sets were analysed with the $R$ software [49], for each trait an analysis of variance (ANOVA) was performed with the following model:

$$
Y_{i j}=\mu+I_{i}+r_{j}+I r_{i j}+\varepsilon i_{j}
$$

With $Y_{i j}$ the trait which is being studied, $\mu$ the mean value for this trait, $I_{i}$ the individual genotype, $r_{j}$ the replication, $I r_{i j}$ the interaction and $\varepsilon_{i j}$ the residual. For the following analyses, $I r_{\mathrm{ij}}$ was included in the residual.

The following hypotheses were verified after the variance analyses.

$\varepsilon \sim N\left(o, \sigma^{2}\right) \rightarrow \operatorname{cov}\left(\varepsilon, \varepsilon^{\prime}\right)=0$ Homoscedasticity (homogeneity of $\operatorname{var}(\varepsilon)$ )

Broad sense heritability is defined by the following formula:

$$
H^{2}=\frac{\sigma_{g^{2}}}{\sigma_{g^{2}}+\sigma_{e^{2}}}
$$

With $H^{2}$ the heritability, $\sigma_{g^{2}}$ genotypic variance and $\sigma_{e^{2}}$ residual variance.

The correlation between traits was also studied using the Bravais-Pearson correlation.

\subsection{Genotyping RxCS}

The wheat population was genotyped on two different single nucleotide polymorphism(SNP) arrays, the Breedwheat Affymetrix Axiom 410K array $[50,51]$ and the Illumina Infinium iSelect Wheat $90 \mathrm{~K}$ array [52].

\subsubsection{Axiom $410 \mathrm{~K}$}

In total, 429 individuals from the RxCS population were genotyped on the Axiom $410 \mathrm{~K}$ array in two sets of 282 and 147. Among these, 236 individuals were randomly selected for further phenotyping. DNA extraction and genotyping were performed by the Gentyane platform (INRAE, Clermont-Ferrand, France).

\subsubsection{ISelect $90 \mathrm{~K}$}

For genotyping on the iSelect 90K array, 159 individuals chosen randomly among $\mathrm{RxCS}$ and both parental varieties were genotyped. DNA extraction and genotyping were performed at TraitGenetics GmbH (Gatersleben, Germany).

\subsection{Genetic Analyses}

\subsubsection{Construction of an Ultra-Dense Genetic Map}

Markers were re-named so as to be tagged with their SNP array of origin and the chromosome they most likely mapped to as this made following steps more straightforward. There are 13,462 markers in common between the $90 \mathrm{~K}$ array and the $410 \mathrm{~K}$ array. These were considered to be distinct for map construction. Out of a total of 409,695 SNP, were kept for the map building file only those that were polymorphic and for which the information from both parents was available, leading to a total of 194,630 SNP. Additionally, only 142 individuals' information was used for map construction as for 17 individuals, genotyping on the $90 \mathrm{~K}$ had done poorly.

The file comprising all polymorphic markers from the TaBW410K and the iSelect $90 \mathrm{~K}$ arrays was input into the Multipoint ultra-dense software developed by MultiQTL Ltd. (Haifa, Israel) at Haifa University in Israel. This software allows ultra-dense genetic maps to be built and is based on the "twin algorithm" [53]. A stringent filter for missing data was applied, all SNP with over 5\% missing data were filtered out. Then, a filter to correct any potential segregation distortion was applied; it was less stringent, allowing a Chi2 up to 9.5. After the first clustering, linkage groups, which belonged to the same chromosome, were merged and the results from Multipoint were transformed with the Kosambi mapping function [54]. The linkage map was graphically visualized with Mapchart V2.3 [55]. 


\subsubsection{Linkage Analysis}

A linkage analysis was carried out using the R/qtl software [56] version 1.42-8. This analysis included for each trait an initial Simple Interval Mapping (SIM), followed by a Composite Interval Mapping (CIM). Analyses were performed replication by replication and set by set (sets only concerning the first lot of phenotypic data). For SIM, 1000 genomewide permutations were used to calculate the significant logarithm of odds (LOD) threshold. Only QTL that showed $p$-values $<0.05$ were considered significant. The CIM was carried out with the SNP with the highest LOD at QTL peaks used as a covariate. When there were several significant QTL detected, the CIM was recalculated with two covariates, however, this never led to any extra detections. QTL intervals were evaluated with the LOD support interval with a drop in LOD of 1 and the "expandtomarkers" argument as true. QTL effects were calculated with the "effectplot" and "effectscan" functions. Possible epistatic interactions between QTL were looked into using the "addint" function.

\subsubsection{QTL Gene Content}

The gene content of the QTL regions was analysed using the IWGSC RefSeq v1.1 annotation, which is anchored on the IWGSC RefSeq v1.0 assembly (both available at https: / / wheat-urgi.versailles.inra.fr/; accessed on 3 December 2021). We specifically searched for the content in wall-associated kinases (WAK), and nucleotide-binding and leucine-rich repeats (NB-LRR) type genes using the IWGSC's 2018 work on manually curated gene families [32] and we searched through the annotated genes using the keyword "kinase". By using the Wheat Expression Browser powered by expVIP (http:/ / www.wheat-expression. $\mathrm{com} /$; accessed on 3 December 2021) $[57,58]$ we were able to access transcriptional data for each of the listed genes in a kinetic of STB infected plants. The data available was for the cultivar Riband at 1, 4, 9, 14, and 21 dpi infected with fungal strain IPO323 [59]. This cultivar is regarded as a good positive control for Z. tritici infection as it is highly susceptible to the disease, moreover, it does not carry the major resistance gene $S t b 6$, unlike Chinese spring for instance [60]. To compare with known STB resistance genes, we included the expression data for Stb6 and Stb16q, respectively known as TraesCS3A02G049500 and TraesCS3D02G500800 in the RefSeq v1.1 annotation.

\section{Results}

\subsection{Description of Phenotypes}

Two phenotypic data sets were acquired on the Renan $\times$ Chinese-Spring population for the isolates I05 and I07. The first data set was collected in 2017 on 236 RILs with two replications, and the second data set was collected in 2018 on 148 RILs with three replications. Overall, distributions of phenotypic traits within the population are similar between replications, and Renan is consistently more resistant than Chinese Spring (Figures S1 and S2). The second replication from the 2018 data set of isolate I05 stands out as being quite different from the others, in particular for S26 and AUDPCS. For this replication, the level of infection was lower than for the other replications and heterogeneous, suggesting that infection failed. Therefore, the following analyses were performed excluding the data from this particular replication, leaving only two replications for the 2018 data set of isolate I05. It is also important to notice that distributions are not bi-modal; phenotypes follow a continuous distribution indicating the presence of several genes with quantitative effect. Only for S26 in 2018, for both isolates I05 and I07, does the distribution not look strictly continuous, but rather skewed towards susceptibility. Finally, the parental phenotypes do not mark the limits of the distribution. Transgressive individuals can be observed for the great majority of studied traits indicating that despite Chinese Spring being susceptible to both fungal strains, it can carry small effect resistance QTL. Correlation coefficients were calculated from mean values between replications using the Bravais-Pearson correlation coefficient (Figure 1). For these analyses, the 2017 sets were analysed together. Overall, AUDPCN, AUDPCS, S20, S26 and PYC (only 2017 data) were all strongly correlated. AUDPCG was poorly correlated to the other traits, except for the 
2018 I07 data, where it is strongly negatively correlated to the other traits. Overall, the S14 and NBS traits were poorly correlated to the other traits. This is certainly due to the low values and low variability in S14 data, and the low reproducibility in NBS data. These results suggest a potential common genetic base for all of the studied traits.

I05

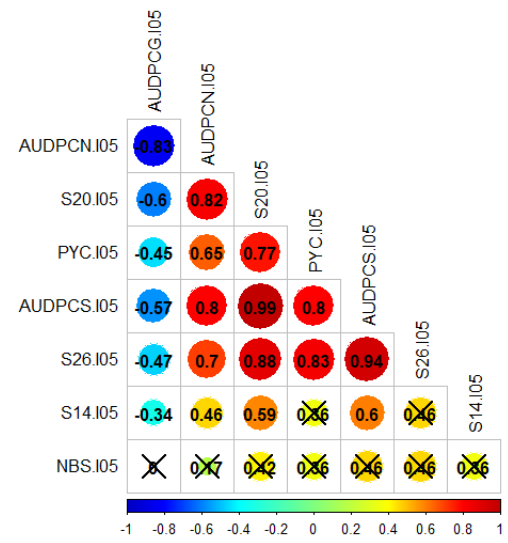

I05

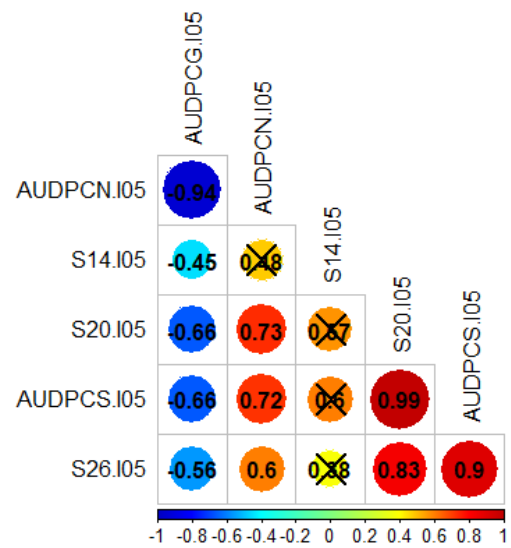

I07

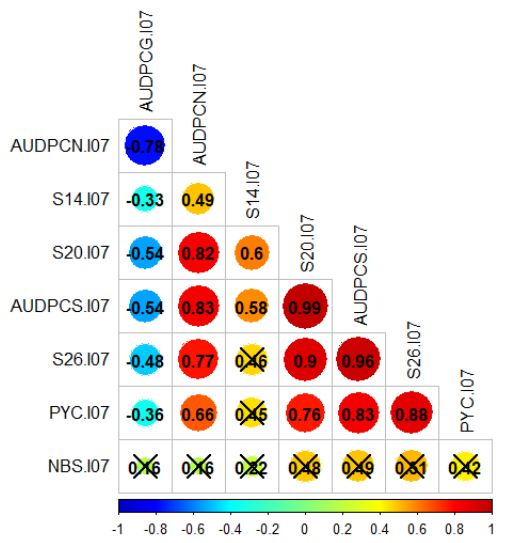

2018

I07

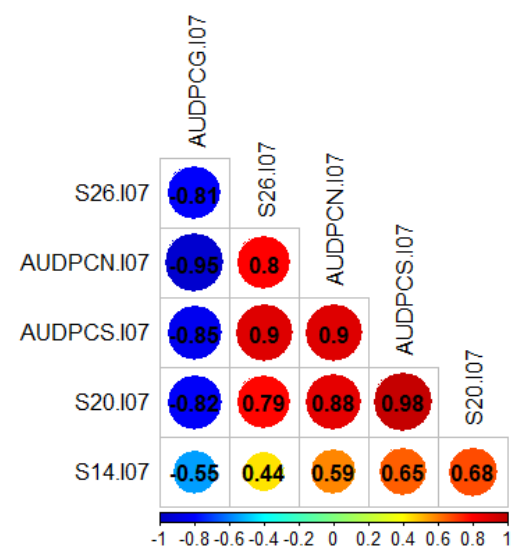

Figure 1. Bravais-Pearson correlograms for the four datasets; crossed out correlation values are not statistically significant $(p$-value $<0.05$ ). The left column presents the phenotypic trait correlations for RxCS inoculated with I05, the right presents the phenotypic trait correlations for RxCS inoculated with I07. PYC is the pycnidia density. NBS is the number of spores per pycnidiospore. AUDPCG is the area under the disease progress curve for the green leaf area. AUDPCN is the area under the disease progress curve for the necrotic leaf area. AUDPCS is the area under the disease progress curve for the sporulating leaf area. S14, S20, and S26 are the sporulating leaf area at 14, 20, and 26 days post-inoculation respectively.

The ANOVA results show that the individual genotype systematically had a significant effect on the phenotype in all cases but I05_2017/1 S14 and NBS, and I07_2017/2 S14 (Table 2). The replication overall had a strong effect on phenotypes, except for the I07_2017/2. Subsequent linkage analyses were therefore carried out replication by replication. Broad-sense heritability was calculated for all traits and was systematically higher for I07 data than for I05 data (Table 2). As the ANOVA assumptions are not respected in all cases, low heritability value does not necessarily indicate that the trait will not lead to the detection of resistance QTL. 
Table 2. Statistical analysis of the phenotypic data for each dataset

\begin{tabular}{|c|c|c|c|c|c|c|c|c|c|}
\hline Isolate Set & Trait & $\begin{array}{c}\text { Statistical } \\
\text { Significance of } \\
\text { the Genotype }\end{array}$ & $\begin{array}{c}\text { Statistical } \\
\text { Significance of the } \\
\text { Replication }{ }^{1}\end{array}$ & $\mathrm{MSg}^{2}$ & $M S \varepsilon^{3}$ & $\begin{array}{l}\text { Broad-Sense } \\
\text { Heritability }\end{array}$ & $\begin{array}{c}\text { Shapiro-Wilk } \\
\text { Normality Test } \\
\text { on Residuals }\end{array}$ & $\begin{array}{l}\text { Independence of } \\
\text { Residuals }\end{array}$ & $\begin{array}{c}\text { Homoscedasticity Bartlet } \\
\text { Test of Homogeneity of } \\
\text { Variances }\end{array}$ \\
\hline \multirow{7}{*}{ I05_2017/1 } & S14 & & $* * *$ & 27 & 27 & 0.00 & 0.00 & no & 0.04 \\
\hline & S20 & $* * *$ & $* * *$ & 1094 & 444 & 0.42 & 0.11 & yes & 0.14 \\
\hline & AUDPCG & $*$ & $*$ & 51,787 & 35,921 & 0.18 & 0.92 & yes & 0.05 \\
\hline & AUDPCN & $*$ & $*$ & 77,482 & 55,907 & 0.16 & 0.85 & yes & 0.31 \\
\hline & AUDPCS & $* * *$ & $* * *$ & 83,562 & 32,115 & 0.44 & 0.11 & yes & 0.26 \\
\hline & PYC & $* * *$ & & 21,769 & 9037 & 0.41 & 0.29 & yes & 0.29 \\
\hline & NBS & & $* * *$ & $1,003,915$ & 868,109 & 0.07 & 0.00 & yes & 0.05 \\
\hline \multirow{8}{*}{ I07_2017/1 } & S14 & & $* *$ & 2 & 2 & 0.04 & 0.00 & no & 0.00 \\
\hline & S20 & $* * *$ & $* * *$ & 401 & 157 & 0.44 & 0.00 & yes & 0.85 \\
\hline & S26 & $* * *$ & $* * *$ & 765 & 233 & 0.53 & 0.40 & yes & 0.98 \\
\hline & AUDPCG & $* * *$ & & 57,879 & 30,256 & 0.31 & 0.00 & no & 0.00 \\
\hline & AUDPCN & $* * *$ & $* * *$ & 92,012 & 25,943 & 0.56 & 0.95 & yes & 0.77 \\
\hline & AUDPCS & $* * *$ & $* * *$ & 40,045 & 12,909 & 0.51 & 0.00 & yes & 0.97 \\
\hline & PYC & $* * *$ & & 29,153 & 8834 & 0.53 & 0.01 & no & 0.04 \\
\hline & NBS & $* * *$ & & $1,865,055$ & 630,731 & 0.49 & 0.00 & no & 0.00 \\
\hline \multirow{6}{*}{ I05_2017/2 } & S14 & $* * *$ & * & 14 & 7 & 0.34 & 0.00 & no & 0.00 \\
\hline & S20 & $* *$ & . & 533 & 344 & 0.22 & 0.94 & yes & 0.54 \\
\hline & AUDPCN & $*$ & $* * *$ & 62,573 & 42,711 & 0.19 & 0.93 & yes & 0.35 \\
\hline & AUDPCS & $* *$ & . & 44,817 & 26,387 & 0.26 & 0.74 & yes & 0.79 \\
\hline & PYC & $* * *$ & $* * *$ & 22,651 & 12,737 & 0.28 & 0.97 & yes & 0.34 \\
\hline & NBS & $* *$ & $* * *$ & 816,528 & 495,995 & 0.24 & 0.00 & yes & 0.04 \\
\hline \multirow{8}{*}{ I07_2017/2 } & S14 & $* * *$ & & 31 & 13 & 0.42 & 0.00 & no & 0.00 \\
\hline & S20 & $* * *$ & & 1195 & 189 & 0.73 & 0.00 & no & 0.01 \\
\hline & S26 & $* * *$ & & 1411 & 222 & 0.73 & 0.60 & yes & 0.33 \\
\hline & AUDPCG & $* * *$ & & 79,008 & 28,924 & 0.46 & 0.16 & yes & 0.22 \\
\hline & AUDPCN & $* * *$ & & 115,168 & 23,787 & 0.66 & 0.24 & yes & 0.01 \\
\hline & AUDPCS & $* * *$ & & 102,594 & 13,479 & 0.77 & 0.00 & no & 0.03 \\
\hline & PYC & $* * *$ & $* * *$ & 59,415 & 18,267 & 0.53 & 0.82 & yes & 0.65 \\
\hline & NBS & $*$ & ${ }^{*}$ & $1,341,693$ & 906,931 & 0.19 & 0.00 & yes & 0.27 \\
\hline \multirow{6}{*}{$\begin{array}{l}\text { I05_2018 only } \\
\text { replications } 1 \text { and } 3\end{array}$} & S14 & $* *$ & $* * *$ & 140 & 86 & 0.24 & 0.00 & no & 0.00 \\
\hline & S20 & $* * *$ & $* * *$ & 1649 & 747 & 0.38 & 0.28 & yes & 0.94 \\
\hline & S26 & $*$ & $* * *$ & 877 & 661 & 0.14 & 0.00 & no & 0.82 \\
\hline & AUDPCG & $* * *$ & $* * *$ & 32,787 & 17,602 & 0.30 & 0.00 & no & 0.00 \\
\hline & AUDPCN & $* * *$ & $* * *$ & 58,506 & 28,592 & 0.34 & 0.86 & yes & 0.26 \\
\hline & AUDPCS & $* * *$ & $* * *$ & 115,164 & 50,508 & 0.39 & 0.66 & yes & 0.65 \\
\hline
\end{tabular}


Table 2. Cont.

\begin{tabular}{|c|c|c|c|c|c|c|c|c|c|}
\hline Isolate Set & Trait & $\begin{array}{c}\text { Statistical } \\
\text { Significance of } \\
\text { the Genotype }\end{array}$ & $\begin{array}{l}\text { Statistical } \\
\text { Significance of the } \\
\text { Replication }{ }^{1}\end{array}$ & $\mathrm{MSg}^{2}$ & $\operatorname{MS} \varepsilon^{3}$ & $\begin{array}{l}\text { Broad-Sense } \\
\text { Heritability }\end{array}$ & $\begin{array}{c}\text { Shapiro-Wilk } \\
\text { Normality Test } \\
\text { on Residuals }\end{array}$ & $\begin{array}{c}\text { Independence of } \\
\text { Residuals }\end{array}$ & $\begin{array}{c}\text { Homoscedasticity Bartlett } \\
\text { Test of Homogeneity of } \\
\text { Variances }\end{array}$ \\
\hline \multirow{5}{*}{ I07_2018 } & S14 & $* * *$ & & 43 & 22 & 0.25 & 0.00 & no & 0.00 \\
\hline & S20 & $* * *$ & $* *$ & 3061 & 368 & 0.71 & 0.00 & no & 0.00 \\
\hline & AUDPCG & $* * *$ & & 144,099 & 32,073 & 0.54 & 0.32 & yes & 0.02 \\
\hline & AUDPCN & $* * *$ & $* *$ & 170,267 & 29,795 & 0.61 & 0.00 & yes & 0.00 \\
\hline & AUDPCS & $* * *$ & $* * *$ & 242,232 & 25,587 & 0.74 & 0.01 & yes & 0.00 \\
\hline
\end{tabular}

${ }^{1}$ Significance codes: $0 * * * *, 0.001^{* * * \prime}, 0.01^{* * \prime}, 0.05^{\prime},{ }^{\prime}, 0.1^{\prime \prime}, 1,{ }^{2} \mathrm{MSg}$ is the mean square value for the individual genotypes output by the ANOVA; ${ }^{3}$ MS $\varepsilon$ is the mean square value for the residuals output by the ANOVA. 


\subsection{An Ultra-Dense Genetic Linkage Map}

We genotyped 159 RILs from the RxCS population with both TaBW410K and iSelect90K arrays. These two arrays share 13,670 common markers, but comparison of parental genotypes between arrays for these common markers revealed an average divergence of $11.1 \%$ for both cultivars. Due to these divergences common markers between both arrays were given different names and considered separately for map construction. Overall, only markers which were polymorphic between both parents and presented no missing data, lack of amplification or heterozygosis for either parent were kept, leading to a total of 183,773 usable markers from the TaBW410K array, representing $43.4 \%$ of the original data set, and a final list of 10,857 markers for the iSelect $90 \mathrm{~K}$ array, representing $13.3 \%$ of the original data set. Consequently, for this population, the rate of polymorphic markers was more than three times higher on the TaBW410K than on the iSelect90K. The 194,630 SNP markers available for map construction were all re-named to show which array they came from and onto which chromosome they were expected to map based on best BLAST values on the reference genome (Chinese Spring). This enabled us to associate linkage groups and corresponding chromosomes more easily when building the map. From the 159 individuals genotyped with both TaBW410K and iSelect $90 \mathrm{~K}$ arrays, 17 individuals were discarded because of their high number of missing data from the iSelect $90 \mathrm{~K}$ genotypes. Moreover, applied filters deleted $13.4 \%$ of the markers, leaving us with a matrix of 142 individuals $x$ 168,522 high quality markers for map construction. After the initial clustering, 25 linkage groups were obtained. Those that corresponded to different parts of the same chromosome were merged. The map we obtained comprised 21 linkage groups, each corresponding to a chromosome (Table 3). It is composed of 5357 genetic bins or unique positions, for a total of 148,820 markers and covers a total genetic distance of 4277 centiMorgans (cM). Table S1 provides the complete map. Of all mapped markers, $3.54 \%$ were skeleton markers, each representing a genetic bin. Of the original number of available markers from the SNP arrays, 30\% were mapped, and of the markers chosen for mapping after all filters, $78 \%$ were mapped. Sub-genomes A and B carry more SNP than sub-genome D. When working with the full set of markers, sub-genome D represents only $16.50 \%$ of this latter set, while A and B sub-genomes represent $42.78 \%$ and $40.72 \%$, respectively. However, subgenome $B$ has a shorter genetic length than either of the other two. The great majority of mapped markers are from the Breedwheat Axiom $410 \mathrm{~K}$ array; indeed, these SNP represent $94.73 \%$ of sub-genome A, $94.61 \%$ of sub-genome B and $97.91 \%$ of sub-genome $\mathrm{D}$. The $90 \mathrm{~K}$ array is particularly underrepresented on the D sub-genome with markers making up a minimum of $0.84 \%$ on chromosome 4 and a maximum of $3.73 \%$ on chromosome 6 . The distance between consecutive markers ranges from $0.35 \mathrm{cM}$ to a maximum of $21.54 \mathrm{cM}$. However, a gap this size is exceptional. Indeed overall, consecutive markers are quite close together, with the average distance between consecutive markers being $0.74 \mathrm{cM}$ in sub-genome A, $0.69 \mathrm{cM}$ in sub-genome B and $1.07 \mathrm{cM}$ in sub-genome $\mathrm{D}$. The third quartile in the distribution of the distance between consecutive markers is 0.72 and $0.71 \mathrm{cM}$ for sub-genomes A and B respectively, while it is slightly higher for sub-genome $\mathrm{D}$ with a value of $1.1 \mathrm{cM}$. In sub-genome $\mathrm{A}$, six gaps in the map are larger than $10 \mathrm{cM}$ on chromosomes $3 \mathrm{~A}, 4 \mathrm{~A}, 5 \mathrm{~A}$ and $7 \mathrm{~A}$. In sub-genome $\mathrm{B}$, only one gap is larger than $10 \mathrm{cM}$ and is on the long arm of chromosome 3B. Moreover, sub-genome $\mathrm{D}$ has four gaps larger than $10 \mathrm{cM}$ on chromosomes 1D, 6D (twice), and 7D.

The comparison between the order of the markers on the genetic map and their assumed physical position shows that, overall, the genetic map follows the assumed physical positions very well (Figure 2). The exception is chromosome $4 \mathrm{D}$, which presents a cluster of markers at the end of the linkage group, which would have been expected to be found in the short arm according to their assumed physical positions (Figure 2). The ratio between genetic and assumed physical positions is also interesting to comment on as it clearly shows the structure of the different chromosomes with SNP distribution following a neat sigmoidal pattern. Indeed, the position of centromeres is marked out by the recombination suppression surrounding them on all chromosomes (Figure 2). 
Table 3. Characteristics of the RxCS genetic linkage map.

\begin{tabular}{|c|c|c|c|c|c|}
\hline \multicolumn{2}{|c|}{ Chromosome } & $\begin{array}{c}\text { Number of } \\
\text { SNP }\end{array}$ & $\begin{array}{l}\text { Number of } \\
\text { Genetic Bins }\end{array}$ & $\begin{array}{l}\text { Map Length } \\
\text { (cM) }\end{array}$ & $\begin{array}{c}\text { Marker Density } \\
\text { (Markers/cM) }\end{array}$ \\
\hline \multirow{7}{*}{ A-genome } & 1 & 10,479 & 358 & 234.44 & 44.7 \\
\hline & 2 & 11,716 & 288 & 189.72 & 61.8 \\
\hline & 3 & 8413 & 302 & 233.28 & 36.1 \\
\hline & 4 & 8465 & 203 & 170.24 & 49.7 \\
\hline & 5 & 6723 & 411 & 312.17 & 21.5 \\
\hline & 6 & 7816 & 226 & 189.03 & 41.3 \\
\hline & 7 & 10,051 & 378 & 273.38 & 36.7 \\
\hline \multicolumn{2}{|l|}{ total A } & 63,663 & 2167 & 1602.26 & 39.7 \\
\hline \multirow{7}{*}{ B-genome } & 1 & 10,503 & 309 & 176.4 & 59.5 \\
\hline & 2 & 9158 & 298 & 197.98 & 46.3 \\
\hline & 3 & 12,016 & 374 & 268.03 & 44.8 \\
\hline & 4 & 5888 & 180 & 140.45 & 41.9 \\
\hline & 5 & 5019 & 234 & 192.98 & 26 \\
\hline & 6 & 10,210 & 173 & 109.66 & 93.1 \\
\hline & 7 & 7803 & 336 & 215.35 & 36.2 \\
\hline \multicolumn{2}{|l|}{ total B } & 60,597 & 1905 & 1300.85 & 46.6 \\
\hline \multirow{7}{*}{ D-genome } & 1 & 3609 & 157 & 172.81 & 20.9 \\
\hline & 2 & 4601 & 134 & 150.27 & 30.6 \\
\hline & 3 & 3512 & 225 & 225.25 & 15.6 \\
\hline & 4 & 2131 & 174 & 156.99 & 13.6 \\
\hline & 5 & 2581 & 203 & 234.75 & 11 \\
\hline & 6 & 4180 & 183 & 204.6 & 20.4 \\
\hline & 7 & 3946 & 211 & 228.97 & 17.2 \\
\hline \multicolumn{2}{|l|}{ total D } & 24,560 & 1287 & 1373.64 & 17.9 \\
\hline \multicolumn{2}{|l|}{ Total } & 148,820 & 5357 & 4276.75 & 34.8 \\
\hline
\end{tabular}

\subsection{Mapping QTL for Resistance}

The analyses of the 2017 and 2018 datasets lead to the detection of several QTL on eight different chromosomes. Among these, only three were detected more than once throughout the analyses, we will therefore focus on these three. The complete linkage analysis results can be found in Table S2. The three robust QTL were detected on chromosomes 1D, 5D and 7B (Tables 4 and 5). The parent carrying the resistant allele is Renan for all three QTL. The QTL however, do not impart resistance to the same strains. Indeed, Qstb.renan-1D imparts resistance to I05 while Qstb.renan-5D imparts resistance to I07 and Qstb.renan-7B is effective against both strains. Qstb.renan-7B explained up to $32 \%$ of phenotypic variation with a mean $\mathrm{r}^{2}$ value of $20 \%$ when detected with the 2017 datasets and up to $38 \%$ with a mean value of $21 \%$ when detected with the 2018 datasets. Qstb.renan-1D was detected the fewest times out of the three repeatable QTL and explained the least phenotypic variation, between 6 and $13.5 \%$ on average, to a maximum of $15 \%$. This QTL was not detected with the 2017/2 dataset (Figure 3B). Finally, Qstb.renan-5D explained up to $35.5 \%$ of phenotypic variation with a mean $\mathrm{r}^{2}$ value between 15.5 and $26 \%$. We did not identify any QTL trait specificity in the various linkage analyses, as was to be expected regarding the correlations between traits. The traits that led to the most detections are S26, AUDPCS and PYC. The traits associated with the highest $\mathrm{r}^{2}$ values overall are AUDPCN, AUDPCS, S26, and PYC. 
Concatenated results between the 2017 and 2018 data sets result firstly in Qstb.renan-7B that is $50.86 \mathrm{Mb}$ long, spanning $64.62 \mathrm{cM}$. Secondly, Qstb.renan-1D is $4.28 \mathrm{Mb}$ long, covering $17.79 \mathrm{cM}$ and carrying $5 \mathrm{SNP}$ with known physical positions. Finally, Qstb.renan-5D is $312 \mathrm{Mb}$ long, spanning $28.58 \mathrm{cM}$. The physical intervals were estimated using markers in the QTL with known positions mapping to the chromosome in question. These numbers take into account every detection of each QTL, and therefore include the least precise detections; this explains, in part, the very large intervals. We however do detect maximum LOD score peaks in the same area throughout the analyses (Figures 3 and 4). No significant interactions were detected between QTL.

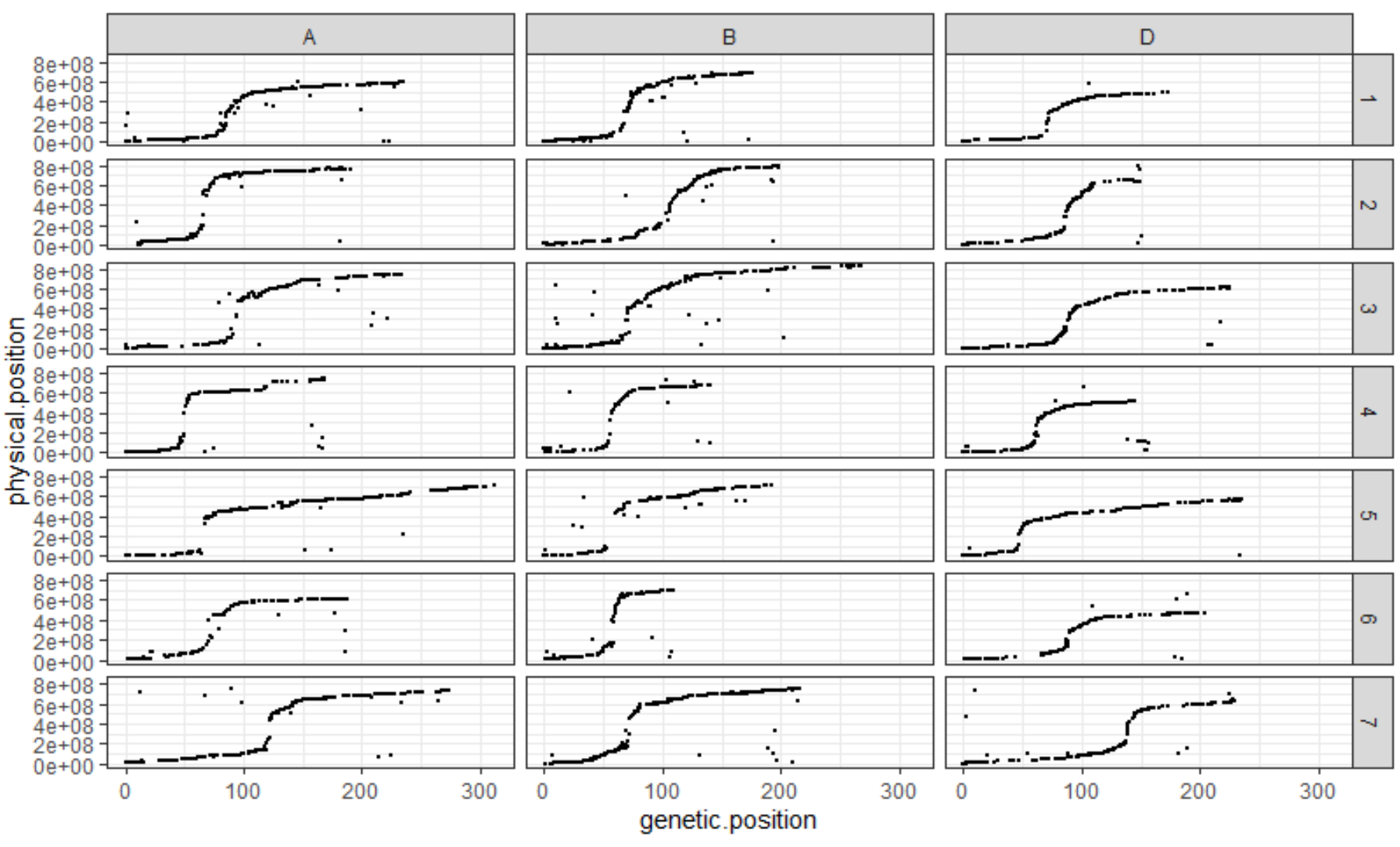

Figure 2. Comparison between markers' genetic and assumed physical positions for each chromosome in each sub-genome. The $x$-axis corresponds to the genetic position of the mapped SNP on the RxCS genetic map in $\mathrm{cM}$. The $y$-axis corresponds to the assumed physical position of the SNP on the chromosome they are on in bp. Each column corresponds to a wheat sub-genome, A, B and $\mathrm{D}$ respectively. Each line corresponds to a chromosome number; the chromosomes are numbered 1 through 7. Each black dot corresponds to a SNP.

\subsection{Gene Content of the QTL}

There are two cloned major resistance genes to STB in wheat to date. The first is Stb6, which encodes a wall-associated kinase-like protein and detects the presence of a matching apoplastic effector [23]. The second is Stb16q, which encodes a cysteine-rich receptor-like kinase and confers broad-spectrum resistance against $Z$. tritici [24]. With this in mind, along with the very large QTL intervals we are working with, we opted to focus on three particular gene families when analysing gene content within the QTL intervals. These families are wall associated kinases (WAK), nucleotide binding leucine-rich receptors (NB-LRR) type genes and genes carrying a kinase domain, all of which have often been associated with disease resistance [24,61]. 
Table 4. QTL for resistance to STB detected with the phenotypic data generated in 2017 and the RxCS genetic map.

\begin{tabular}{|c|c|c|c|c|c|c|c|}
\hline QTL.2017 & $\begin{array}{l}\text { Number of } \\
\text { Detections }\end{array}$ & $\mathbf{r}^{2} \operatorname{Max}(\%)$ & $\begin{array}{c}\text { Mean } r^{2} \\
(\%)\end{array}$ & $\begin{array}{l}\text { Peak Marker Associated with } \\
\mathbf{r}^{2} \text { Max }\end{array}$ & $\begin{array}{l}\text { Parent Carrying the } \\
\text { Resistance Allele }\end{array}$ & Traits & Detected with \\
\hline Qstb.renan-1D & 3 & 7.5 & 6 & cfn1317667_410K_1DS & Renan & S20, S26, AUDPCS & I05 \\
\hline Qstb.renan-5D & 22 & 35.5 & 26 & cfn2823104_410K_5DS & Renan & S20, S26, AUDPCG, AUDPCN, AUDPCS, PYC & I07 \\
\hline
\end{tabular}

Table 5. QTL for resistance to STB detected with the phenotypic data generated in 2018 and the RxCS genetic map.

\begin{tabular}{|c|c|c|c|c|c|c|c|}
\hline QTL.2018 & $\begin{array}{l}\text { Number of } \\
\text { Detections }\end{array}$ & $\mathbf{r}^{2} \operatorname{Max}(\%)$ & $\underset{(\%)}{\operatorname{Mean} r^{2}}$ & $\begin{array}{l}\text { Peak Marker Associated with } \\
\mathrm{r}^{2} \text { Max }\end{array}$ & $\begin{array}{l}\text { Parent Carrying the } \\
\text { Resistance Allele }\end{array}$ & Traits & Detected with \\
\hline Qstb.renan-1D & 5 & 15 & 13.5 & cfn1315024_410K_1DS & Renan & S20, AUDPCN, AUDPCS & I05 \\
\hline Qstb.renan-5D & 18 & 21.5 & 15.5 & cfn2827993_410K_5DS & Renan & S14, S20, S26, AUDPCG, AUDPCN, AUDPCS & I07 \\
\hline Qstb.renan-7B & 22 & 38 & 21 & cfn0916416_410K_7BL & Renan & S14, S20, S26, AUDPCG, AUDPCN, AUDPCS & I05 and I07 \\
\hline
\end{tabular}


A. Set 1
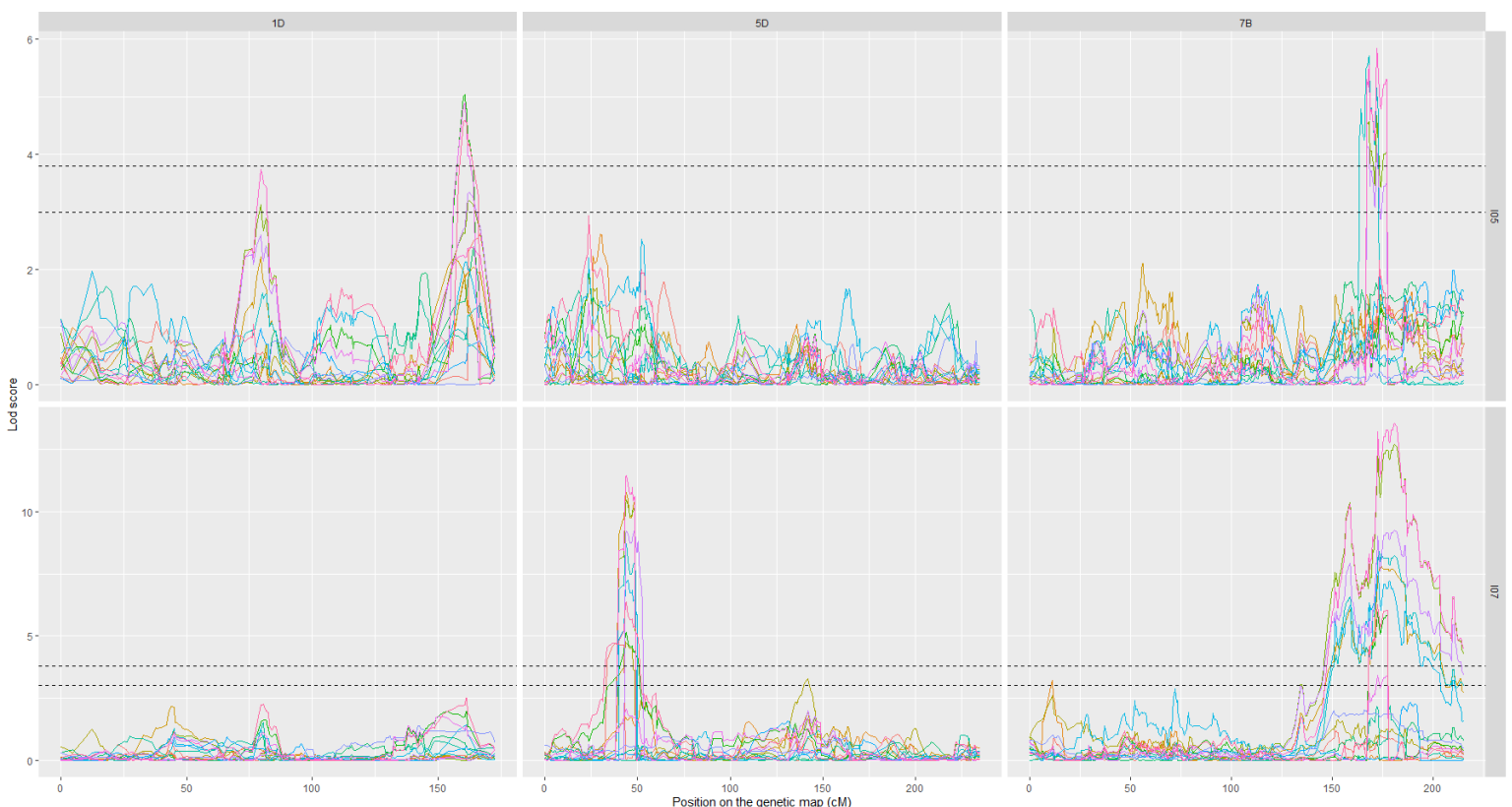

\section{B. Set 2}
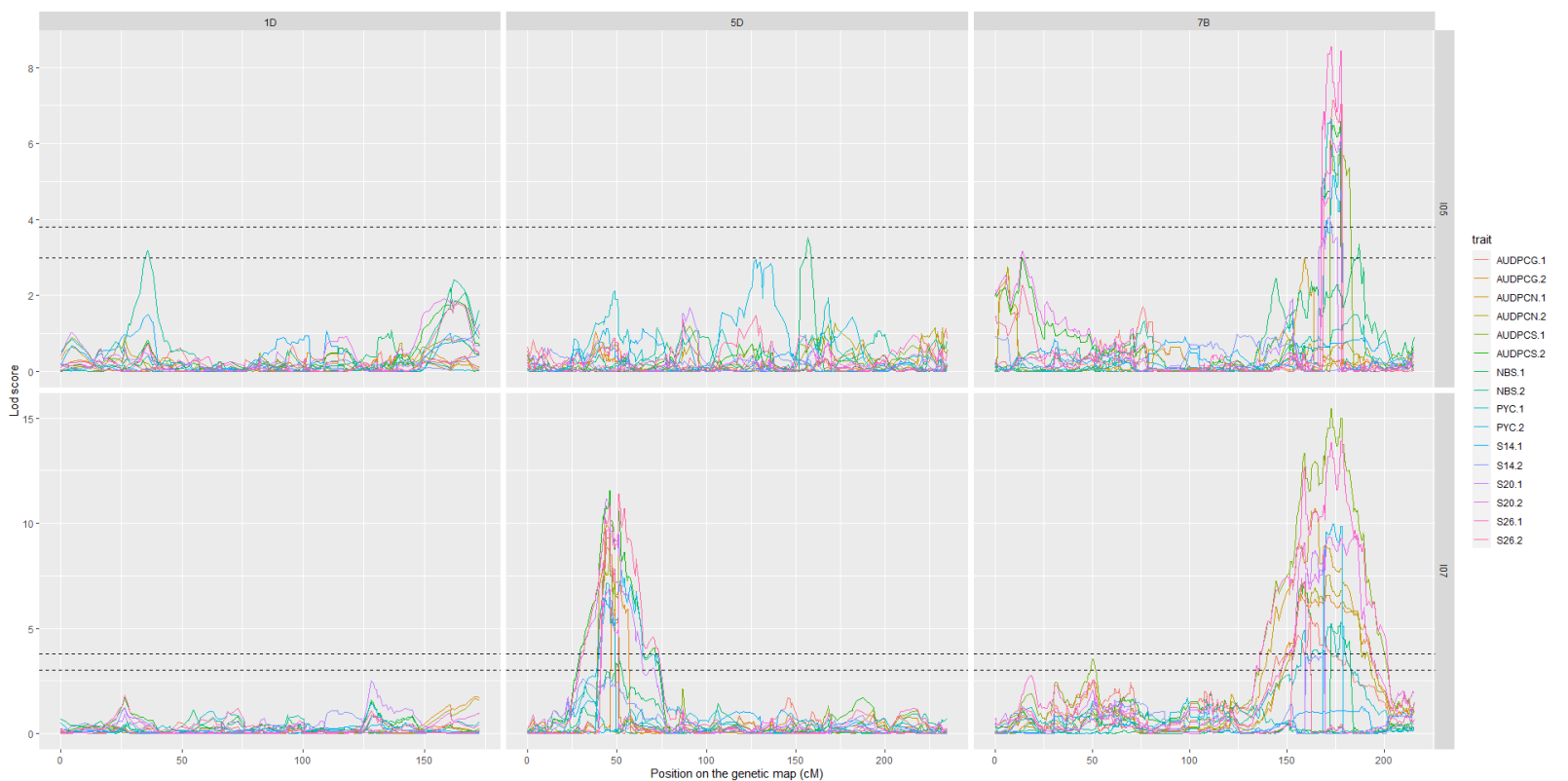

Figure 3. LOD score profiles for the linkage analyses of the 2017 datasets. (A) presents the results for Set 1, (B) presents the results for Set 2. In dotted lines are represented the minimal and maximal LOD threshold values obtained in the linkage analyses after 1000 permutations tests. The $x$-axis represents the position of the markers on the genetic map in cM. The $y$-axis represents the LOD score associated to the markers. Each column corresponds to a chromosome, chromosomes 1D, 5D and 7B respectively. Each line corresponds to a fungal strain, I05 and I07 respectively. The colours in the graphs correspond to the studied traits for each replication. PYC is the pycnidia density. NBS is the number of spores per pycnidiospore. AUDPCG is the area under the disease progress curve for the green leaf area. AUDPCN is the area under the disease progress curve for the necrotic leaf area. AUDPCS is area under the disease progress curve for the sporulating leaf area. S14, S20 and S26 are the sporulating area at 14, 20 and 26 days post-inoculation respectively. Each trait was studied over two replicates, 1 and 2. 


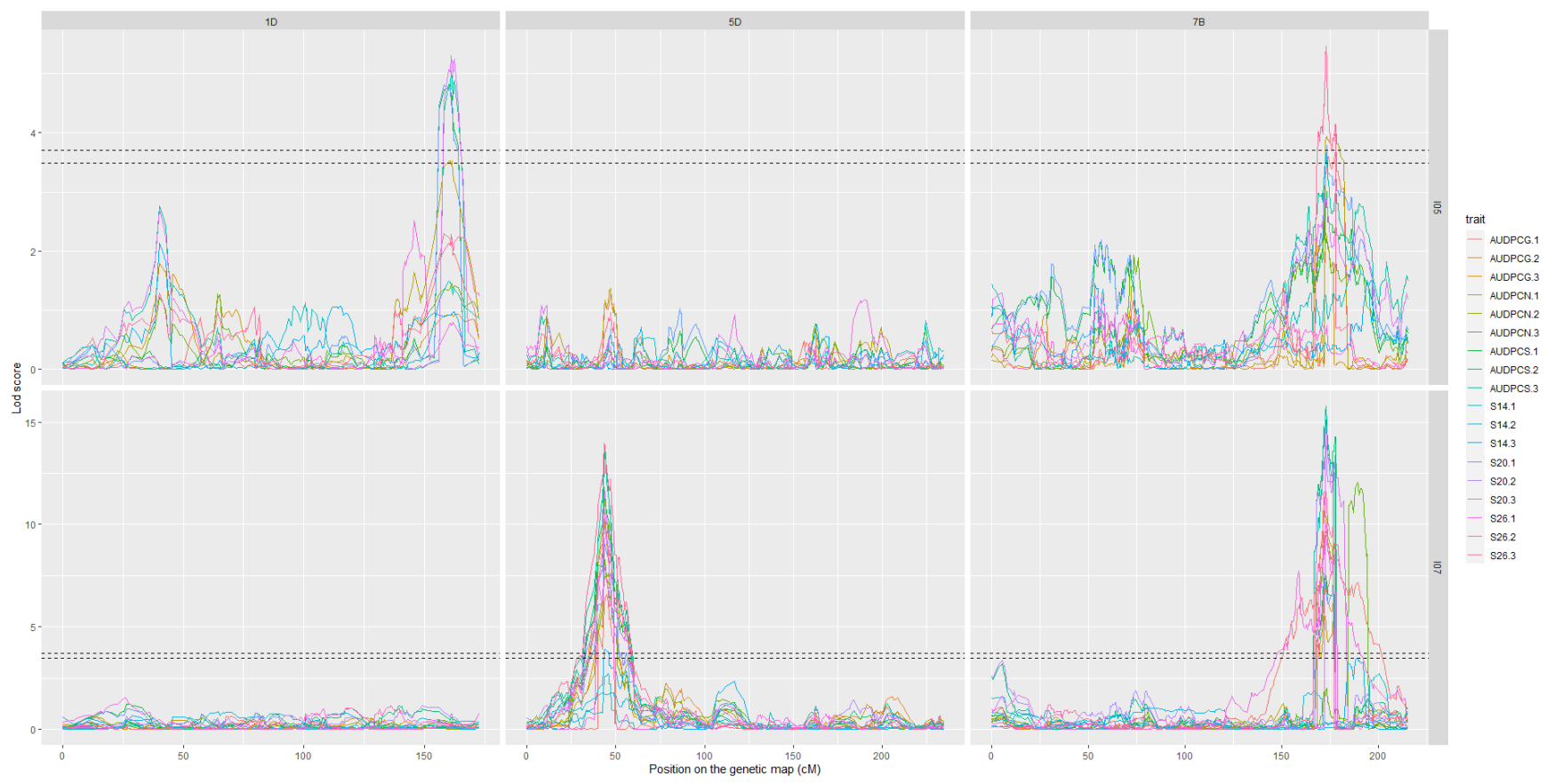

Figure 4. LOD score profiles for the linkage analyses of the 2018 dataset. In dotted lines are represented the minimal and maximal LOD threshold values obtained in the linkage analyses after 1000 permutations tests. The $x$-axis represents the position of the markers on the genetic map in cM. The $y$-axis represents the LOD score associated to the markers. Each column corresponds to a chromosome, chromosomes 1D, 5D, and 7B respectively. Each line corresponds to a fungal strain, I05 and $\mathrm{I07}$ respectively. The colours in the graphs correspond to the studied traits for each replication. AUDPCG is the area under the disease progress curve for the green leaf area. AUDPCN is the area under the disease progress curve for the necrotic leaf area. AUDPCS is area under the disease progress curve for the sporulating leaf area. S14, S20, and S26 are the sporulating area at 14, 20, and 26 days post-inoculation respectively. Each trait was studied over three replicates, 1, 2, and 3.

Qstb-renan-1D holds a total of 141 annotated genes. Of the 141, 25 are NB-LRRtype genes, while 5 are WAKs and one has a kinase domain. Qstb-renan-5D holds 1981 annotated genes, none of which are NB-LRR-type genes. It holds 12 WAKs and 22 genes with kinase domains, two of which are projected to be receptors or receptor-like, these are TraesCS5D02G166400 and TraesCS5D02G181500. Qstb-renan-7B holds 616 annotated genes. This QTL holds no NB-LRR type genes, one WAK, and one gene with a kinase domain. Table 6 presents the details concerning the NB-LRR, WAK and kinase domain carrying genes in the QTL intervals.

With the data extracted from expVIP (http:/ / www.wheat-expression.com/; accessed on 3 December 2021), we were able to see that for a majority of the genes, there was no expression in the inoculated plants. However, for 35 of them, we were able to identify expression patterns over the course of the infection (Figure 5). What we can observe with this data is that for the two known resistance genes Stb6 and Stb16q, expression is maximal at 9dpi, this is also the case for some of the WAK and NB-LRR type genes in the QTL intervals. At 9dpi, the infection is still in the biotrophic phase but at the onset of switching to the necrotrophic phase [62]. For Qstb-renan-1D, these are BST_chr1D_nlr_113, TaWAK40_1D-gene, TaWAK41_1D-gene, TaWAK42_1D-gene, and BST_chr1D_nlr_102. For Qstb-renan-5D, these are TaWAK355_5D-gene, TaWAK356_5D-gene, TaWAK358_5D-gene, and TraesCS5D02G081700. For the two receptor or receptor-like kinases in Qstb-renan-5D, there was no expression. The only gene with any expression in our list for Qstb-renan-7B was TraesCS7B02G466300, which had low expression overall, but it was maximal at $1 \mathrm{dpi}$. 
Table 6. WAK ${ }^{1}$, NB-LRR ${ }^{2}$, and kinase domain carrying genes identified in the three QTL intervals.

\begin{tabular}{|c|c|c|c|c|c|}
\hline QTL & Gene.ID & RefSeq v1.1 ID & Start (bp) & Stop (bp) & Annotation \\
\hline Qstb-renan-1D & BST_chr1D_nlr_115 & TraesCS1D02G015500 & 7277369 & 7280463 & NB-LRR \\
\hline Qstb-renan-1D & BST_chr1D_nlr_114 & TraesCS1D02G016026 & 7381284 & 7384806 & NB-LRR \\
\hline Qstb-renan-1D & BST_chr1D_nlr_113 & TraesCS1D02G016100 & 7419157 & 7422949 & NB-LRR \\
\hline Qstb-renan-1D & BST_chr1D_nlr_9 & TraesCS1D02G016900 & 7592690 & 7609204 & NB-LRR \\
\hline Qstb-renan-1D & BST_pseudo_chr1D_nlr_10 & TraesCS1D02G016983 & 7671168 & 7676063 & NB-LRR \\
\hline Qstb-renan-1D & BST_pseudo_chr1D_nlr_11 & TraesCS1D02G016991 & 7678267 & 7680938 & NB-LRR \\
\hline Qstb-renan-1D & BST_chr1D_nlr_12 & TraesCS1D02G017400 & 7820918 & 7823449 & NB-LRR \\
\hline Qstb-renan-1D & BST_chr1D_nlr_13 & TraesCS1D02G017600 & 7868467 & 7872465 & NB-LRR \\
\hline Qstb-renan-1D & BST_expressed_pseudo_chr1D_nl & TraesCS1D02G018800 & 8226547 & 8230158 & NB-LRR \\
\hline Qstb-renan-1D & BST_pseudo_chr1D_nlr_110 & TraesCS1D02G019600 & 8605145 & 8610344 & NB-LRR \\
\hline Qstb-renan-1D & BST_chr1D_nlr_14 & TraesCS1D02G019700 & 8610887 & 8616204 & NB-LRR \\
\hline Qstb-renan-1D & BST_pseudo_chr1D_nlr_109 & TraesCS1D02G020619 & 8838803 & 8842102 & NB-LRR \\
\hline Qstb-renan-1D & BST_chr1D_nlr_108 & TraesCS1D02G021000 & 9028322 & 9037195 & NB-LRR \\
\hline Qstb-renan-1D & BST_pseudo_chr1D_nlr_106 & TraesCS1D02G021200 & 9086119 & 9091764 & NB-LRR \\
\hline Qstb-renan-1D & BST_pseudo_chr1D_nlr_104 & TraesCS1D02G021751 & 9309301 & 9328352 & NB-LRR \\
\hline Qstb-renan-1D & BST_chr1D_nlr_16 & TraesCS1D02G022500 & 9575753 & 9593333 & NB-LRR \\
\hline Qstb-renan-1D & BST_chr1D_nlr_102 & TraesCS1D02G026000 & 10661025 & 10664946 & NB-LRR \\
\hline Qstb-renan-1D & BST_expressed_pseudo_chr1D_nlr_19 & TraesCS1D02G028700 & 11287245 & 11292876 & NB-LRR \\
\hline Qstb-renan-1D & BST_pseudo_chr1D_nlr_20 & TraesCS1D02G028736 & 11319796 & 11321348 & NB-LRR \\
\hline Qstb-renan-1D & BST_chr1D_nlr_21 & TraesCS1D02G029000 & 11408761 & 11415088 & NB-LRR \\
\hline Qstb-renan-1D & BST_chr1D_nlr_22 & TraesCS1D02G029100 & 11451423 & 11459353 & NB-LRR \\
\hline Qstb-renan-1D & BST_chr1D_nlr_23 & TraesCS1D02G029200 & 11493627 & 11499140 & NB-LRR \\
\hline Qstb-renan-1D & TaWAK38_1D-gene & TraesCS1D02G016200 & 7429822 & 7445013 & WAK \\
\hline Qstb-renan-1D & TaWAK39_1D-gene & TraesCS1D02G016800 & 7583590 & 7587977 & WAK \\
\hline Qstb-renan-1D & TaWAK40_1D-gene & TraesCS1D02G017700 & 7874518 & 7876881 & WAK \\
\hline Qstb-renan-1D & TaWAK41_1D-gene & TraesCS1D02G017800 & 7877418 & 7880329 & WAK \\
\hline Qstb-renan-1D & TaWAK42_1D-gene & TraesCS1D02G017900 & 7896854 & 7899155 & WAK \\
\hline Qstb-renan-5D & TaWAK349_5D-gene & TraesCS5D02G043400 & 42925913 & 42928461 & WAK \\
\hline Qstb-renan-5D & TaWAK350_5D-gene & TraesCS5D02G043500 & 42930408 & 42932902 & WAK \\
\hline Qstb-renan-5D & TaWAK351_5D-gene & TraesCS5D02G043532 & 42944893 & 42947212 & WAK \\
\hline Qstb-renan-5D & TaWAK352_5D-gene & TraesCS5D02G052500 & 50569632 & 50576495 & WAK \\
\hline Qstb-renan-5D & TaWAK353_5D-gene & TraesCS5D02G052800 & 50635242 & 50646756 & WAK \\
\hline Qstb-renan-5D & TaWAK354_5D-gene & TraesCS5D02G061800 & 58138943 & 58142318 & WAK \\
\hline
\end{tabular}


Table 6. Cont.

\begin{tabular}{|c|c|c|c|c|c|}
\hline QTL & Gene.ID & RefSeq v1.1 ID & Start (bp) & Stop (bp) & Annotation \\
\hline Qstb-renan-5D & TaWAK355_5D-gene & TraesCS5D02G061900 & 58143379 & 58149665 & WAK \\
\hline Qstb-renan-5D & TaWAK356_5D-gene & TraesCS5D02G062100 & 58151124 & 58155524 & WAK \\
\hline Qstb-renan-5D & TaWAK357_5D-gene & TraesCS5D02G062200 & 58226914 & 58230221 & WAK \\
\hline Qstb-renan-5D & TaWAK358_5D-gene & TraesCS5D02G062600 & 58419864 & 58422609 & WAK \\
\hline Qstb-renan-5D & TaWAK359_5D-gene & TraesCS5D02G073900 & 72901902 & 72907097 & WAK \\
\hline Qstb-renan-5D & TaWAK360_5D-gene & TraesCS5D02G096200 & 106519841 & 106525422 & WAK \\
\hline Qstb-renan-7B & TaWAK556_7B-gene & TraesCS7B02G463200 & 720131495 & 720134235 & WAK \\
\hline Qstb-renan-1D & TraesCS1D02G026200 & TraesCS1D02G026200 & 10715309 & 10722269 & Probable serine/threonine-protein kinase WNK3 \\
\hline Qstb-renan-5D & TraesCS5D02G060900 & TraesCS5D02G060900 & 57843934 & 57851315 & Non-specific serine/threonine protein kinase \\
\hline Qstb-renan-5D & TraesCS5D02G065700 & TraesCS5D02G065700 & 61052683 & 61060726 & Phosphatidylinositol 3-kinase VPS34 \\
\hline Qstb-renan-5D & TraesCS5D02G068700 & TraesCS5D02G068700 & 65753632 & 65755248 & Non-specific serine/threonine protein kinase \\
\hline Qstb-renan-5D & TraesCS5D02G069700 & TraesCS5D02G069700 & 67578001 & 67588803 & pfkB-like carbohydrate kinase family protein \\
\hline Qstb-renan-5D & TraesCS5D02G081700 & TraesCS5D02G081700 & 82186877 & 82189457 & $\begin{array}{l}\text { Serine/threonine protein kinase } \% 2 \mathrm{C} \text { Abscisic acid (ABA)-activated protein } \\
\text { kinase } \% 2 \mathrm{C} \text { Hyperosmotic stress response } \% 2 \mathrm{C} \text { ABA signal transduction }\end{array}$ \\
\hline Qstb-renan-5D & TraesCS5D02G089700 & TraesCS5D02G089700 & 97036711 & 97041067 & Diacylglycerol kinase \\
\hline Qstb-renan-5D & TraesCS5D02G091000 & TraesCS5D02G091000 & 98227410 & 98230028 & L-type lectin-domain containing receptor kinase S.4 \\
\hline Qstb-renan-5D & TraesCS5D02G104600 & TraesCS5D02G104600 & 118455172 & 118460088 & Nucleoside diphosphate kinase \\
\hline Qstb-renan-5D & TraesCS5D02G104900 & TraesCS5D02G104900 & 118834967 & 118838504 & ATP-dependent 6-phosphofructokinase \\
\hline Qstb-renan-5D & TraesCS5D02G140700 & TraesCS5D02G140700 & 224325320 & 224328774 & Phosphatidylinositol 4-phosphate 5-kinase \\
\hline Qstb-renan-5D & TraesCS5D02G144800 & TraesCS5D02G144800 & 231350992 & 231353762 & Non-specific serine/threonine protein kinase \\
\hline Qstb-renan-5D & TraesCS5D02G145100 & TraesCS5D02G145100 & 231743581 & 231750603 & Mitogen-activated protein kinase \\
\hline Qstb-renan-5D & TraesCS5D02G166400 & TraesCS5D02G166400 & 259233864 & 259236422 & Receptor like protein kinase S.2 \\
\hline Qstb-renan-5D & TraesCS5D02G181500 & TraesCS5D02G181500 & 282151742 & 282156543 & $\mathrm{BR}$ receptor kinase $\% 2 \mathrm{C}$ Brassinosteroid (BR) perception in the roo \\
\hline Qstb-renan-5D & TraesCS5D02G191900 & TraesCS5D02G191900 & 294637785 & 294639948 & $\mathrm{NAD}(\mathrm{H})$ kinase 3 \\
\hline Qstb-renan-5D & TraesCS5D02G203600 & TraesCS5D02G203600 & 308863403 & 308865114 & Serine/threonine-protein kinase BLUS1 \\
\hline Qstb-renan-5D & TraesCS5D02G214300 & TraesCS5D02G214300 & 323911872 & 323914256 & Serine/threonine-protein kinase \\
\hline Qstb-renan-5D & TraesCS5D02G232500 & TraesCS5D02G232500 & 339652596 & 339654075 & Non-specific serine/threonine protein kinase \\
\hline Qstb-renan-5D & TraesCS5D02G232600 & TraesCS5D02G232600 & 339712134 & 339713477 & Non-specific serine/threonine protein kinase \\
\hline Qstb-renan-5D & TraesCS5D02G234000 & TraesCS5D02G234000 & 341192646 & 341202493 & ATP-dependent 6-phosphofructokinase \\
\hline Qstb-renan-7B & TraesCS7B02G466300 & TraesCS7B02G466300 & 723900282 & 723903056 & Serine/threonine-protein kinase \\
\hline
\end{tabular}

${ }^{1}$ Wall-associated kinases (WAK); ${ }^{2}$ Nucleotide-binding and leucine-rich repeats (NB-LRR); Genes highlighted are the candidate genes found in common with Yang et al. (2018) [16]. 


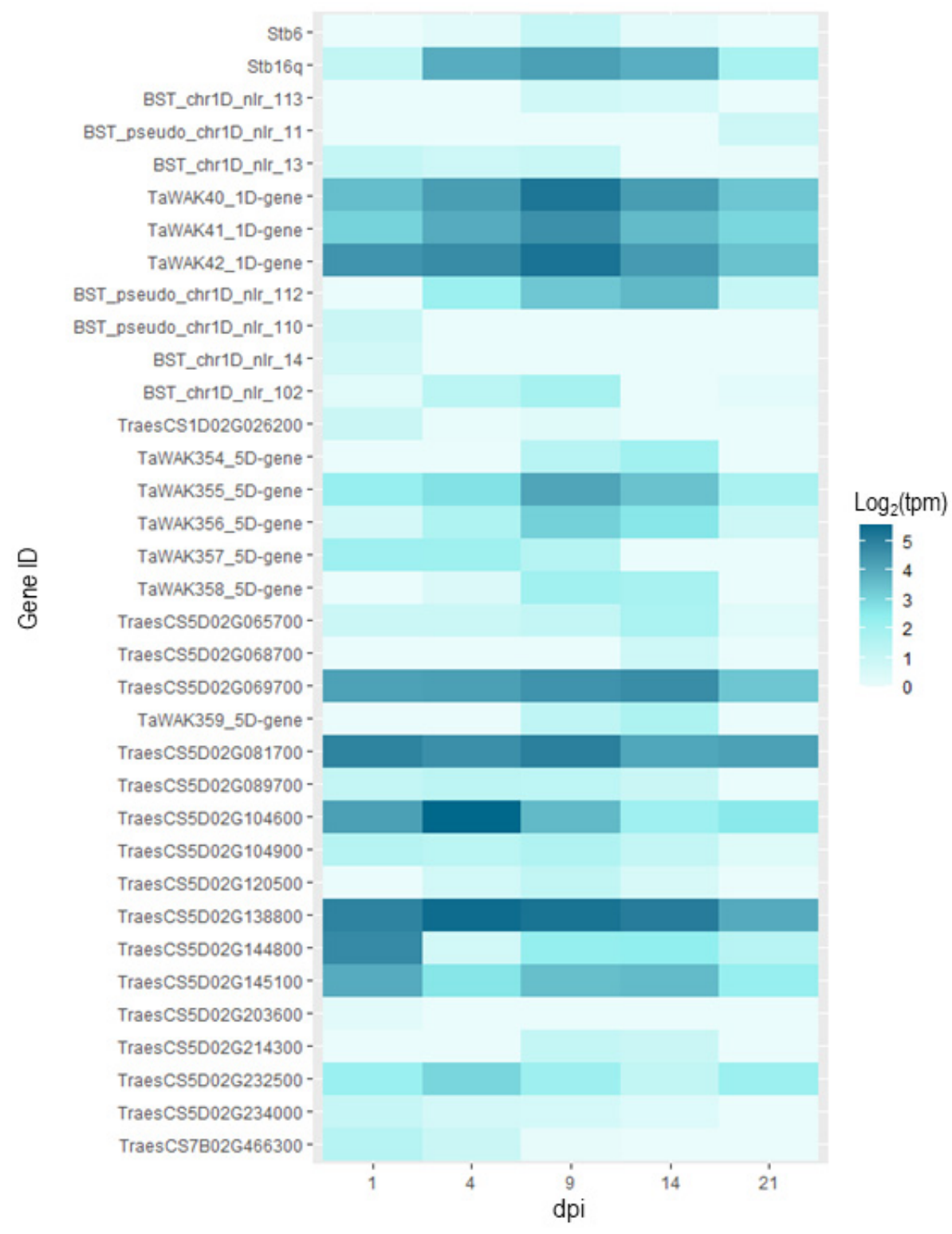

Figure 5. Heatmap representing the expression for each candidate gene where expression values were not equal to zero for the cultivar Riband inoculated with fungal strain IPO323. The $x$-axis represents post inoculation days, 1, 4, 9, 14, and 20 dpi respectively. The expression data is expressed in $\log _{2}(\mathrm{tpm})$, with tpm transcripts per million. The first two lines present the data for $S t b 6$ and Stb16q for reference. The subsequent lines represent the candidate genes, which are ordered by physical position, top to bottom. The data represented here was extracted from http://www.wheat-expression.com/; accessed on 3 December 2021.

\section{Discussion}

\subsection{An Ultra-Dense Genetic Map Built from Two SNP Arrays}

In this study, we built an ultra-dense genetic linkage map for bread wheat from the RxCS population. The map we obtained boasts 5357 unique positions for a total of 148,820 mapped markers. At present, this is the most densely marked genetic map built from a single segregating population. It does contain eleven gaps that are larger than $10 \mathrm{cM}$, which could hinder the detection of QTL in these regions. Moreover, for the most part the assumed physical position of the markers and their order in the genetic map corresponds well. There is a cluster of markers on chromosome 4D that mapped on the long arm of the chromosome while their physical position is assigned to the short arm. This could be due to chromosomal rearrangements between Chinese Spring and Renan, although the 
D sub-genome is not the most prone of the three to chromosomal rearrangements $[63,64]$. The Renan-Chinese Spring genetic map built by Rimbert et al. (2018) [65] corroborates the marker ordering we find with this map for chromosome $4 \mathrm{D}$ and indeed for the rest of the genome (Figure S3). Finally, a recent refined assembly of Chinese Spring [33] includes several major corrections at the $4 \mathrm{D}$ long arm telomere, suggesting that the misplacement is indeed due to errors in the original assembly.

Two studies, which used only Illumina Infinium iSelect $90 \mathrm{~K}$ markers, provide a good base for comparison with the map we built here. The first is that of Wang et al. (2014) [52] which was the first built with this array. They built a consensus map using six doubled haploid mapping populations; the map contains 40,267 markers distributed in 5564 genetic bins. In the genetic maps that they built for their various mapping populations, the majority of markers were to be found in the A and B sub-genomes while the D sub-genome represented a mere $15 \%$ of mapped markers, consistent with what we found in this study. The order of the markers in our map is for the most part consistent with that in Wang et al. (2014) [52] (Figure S4). The second study we used for comparison is that of Wen et al. (2017) [66]. They built a consensus map comprising 29,692 markers distributed in 8960 bins; it was built with the maps of four mapping populations genotyped with the Illumina Infinium iSelect $90 \mathrm{~K}$ array and five maps from previous reports. Firstly, all four of their maps consistently have a lower number of markers on the D sub-genome than on sub-genomes $\mathrm{A}$ and $\mathrm{B}$, with the percentage of total markers on the D-sub-genome ranging from $7.64 \%$ to $12.8 \%$, this corroborates with our results and other studies which show lower diversity in the D sub-genome [66-68]. The total number of markers on each map is 10,986 for 2840 bins, 11,819 for 3242 bins, 9824 for 3198 bins and 14,862 for 3460 bins. The map presented here carries a total of 148,820 markers for 5357 bins. It is therefore very densely covered and rivals the Wang et al. (2014) [52] consensus map in terms of unique genetic positions despite being a map built from a single mapping population. Its particularity lies in the fact that two different SNP arrays were used to construct it, the TaBW410K Breedwheat array and the Illumina Infinium iSelect Wheat 90K array. The final RxCS map contains $95 \%$ of markers from the TaBW410K Breedwheat array and only 5\% from the second array, this can in part be explained by the fact that the markers constituting both arrays were not chosen following the same strategies. For the TaBW410K Breedwheat array, a particular effort was made to target polymorphic markers, notably in modern wheat cultivars. Though the Infinium iSelect Wheat 90K array SNP in the RxCS genetic map are fewer compared to those of the Breedwheat array, they are present throughout the map on sub-genomes A and B (Figure S5A). Both arrays therefore contribute to the map's construction and structure (Figure S5). The 13,670 SNP markers, which are supposedly common to both arrays, do not often appear in the same genetic bins, though they do for the most part appear at close genetic positions. Indeed, out of 13,670, only 33 markers appear in the same bin as their counterpart in the other array. The average distance overall between two paired markers is $3.19 \mathrm{cM}$, while the median value is $2.27 \mathrm{cM}$. In one exceptional case, that of BS00044983_51, the markers of the pair do not appear on the same chromosome but on the homoeologous chromosomes 2B and 2D. The largest gap between a pair of markers, which are mapped on the same chromosome, is $21.1 \mathrm{cM}$ and is the case for marker BobWhite_c12355_1548. In total, 27 marker pairs are more than $10 \mathrm{cM}$ apart. This could be due to error rates between genotyping experiments, slightly different scoring methods for SNP calling between the arrays or indeed duplications in the sequence. All these results in addition to the very low number of mapped markers from the iSelect Wheat 90K array shows that the TaBW410K Breedwheat array performs better as a base for mapping.

As of yet, this is the only map which carries markers from both of the SNP arrays previously mentioned. As such, this map can be used as a "bridge" to compare maps from studies using only one or the other SNP array. 


\subsection{Phenotypic Traits Involved in the Resistance of Renan to STB}

All of the experiments presented here were carried out in controlled conditions at the seedling stage. This simplifies phenotyping as, in field conditions, other diseases with similar symptoms to STB can infect crops. Septoria nodorum blotch caused by fungal pathogen Parastagonospora nodorum in particular can lead to confusion [69]. Other external factors such as environmental variations can also greatly impact field conditions, compromising experiments' success [70]. Another reason for choosing to work in controlled conditions is that quantitative interactions can be highly variable within and between experiments $[44,45,71]$, controlled conditions allow one to reduce background variation that might exist in field conditions, although it is not completely suppressed. As the values for S26, AUDPC for green area, necrotic area, and sporulating area were all generated using data from visual symptom assessments, it was necessary to reduce background noise as much as possible, this included always having the same person perform the assessments within a triplicated or duplicated experiment. These precautions allowed us to obtain data, which though not necessarily normally distributed or statistically repeatable according to ANOVA results, enabled us to identify reliable QTL when comparing overall results. Precision phenotyping with image analyses has already been used successfully for studying the Z. tritici/wheat interaction [46]; it is suggested that pycnidia counting and size evaluation could be helpful in evaluating the epidemic potential of fungal strains and that the host can influence these traits. Yates et al. (2019) [21] identified previously undetected loci for quantitative resistance to STB using the ImageJ macro for four phenotypic traits evaluated on a GWAS panel of 335 European winter wheat cultivars infected with a natural highly diverse $Z$. tritici population. In our case, though the PYC trait corresponding to pycnidia density did enable us to detect QTL, these were not different to the ones we were already able to identify using the visual assessment data. Precision phenotyping with a particle counter has also previously been used successfully in the Z. tritici/wheat interaction. Boixel, et al. (2019) [72] evaluated the number of spores in a sample and they also evaluated spore size, shape and melanisation. They showed that for spore counting, the particle counter is a good means of gaining in accuracy and with the study of morphological variation between spores, they provide insight into more phenotypic traits that could be accessed by using a particle counter. Particle counters have been used in the study of the Melamspora larici-populina/poplar interaction [73], the Phytophthora infestans/potato interaction [74] and the two main species of the ascochyta blight complex of pea/pea interaction [75]. In this latter case, the particle counter's image analysis capacities were used to evaluate spore length. This type of phenotyping offers a large diversity of potential phenotypic traits, which could lead to the identification of novel QTL, however, much as for PYC, the sporulation trait NBS did not yield the results we had hoped for, however it did confirm the QTL that we could already identify with our visual assessment data. These traits have previously led to the detection of QTL that were different to those detected with visually acquired data, however this was in the context of a GWAS with a diversified panel of cultivars [21].

\subsection{Quantitative Resistance Durability Is a Multi-Layered Issue}

Our objective was to identify regions in the T. aestivum genome, which could carry genes that contribute to quantitative resistance to STB. The continuous distribution of phenotypes that we observed in our data is indeed indicative of a quantitative and polygenic type of resistance (Figures S1 and S2). We were able to identify three robust QTL on chromosomes $1 \mathrm{D}, 5 \mathrm{D}$, and $7 \mathrm{~B}$, each explaining between $6 \%$ to $26 \%$ of the phenotypic variation on average. These quantitative and polygenic attributes contribute to resistance durability for several reasons. Firstly, quantitative resistance, in theory, exerts less selection pressure on pathogen populations, meaning that the latter are less likely to adapt in the short term [76]. Secondly, the polygenic nature of quantitative resistance provides more arguments for durability and is illustrated in the present case by the identification of three different QTL. Polygenic resistance is more durable as it is a combination of factors which 
provides resistance, rendering adaptation to each of these factors more complex [77]. This can be illustrated with studied cases of viral plant pathogens where the higher the number of mutations required for virulence is, the lower the probability of adaptation gets, and therefore polygenic resistance is more durable than monogenic [78-80]. In the case of the Capsicum anuum/Potato virus $Y$ in particular, it was shown that polygenic resistance breakdown is slower than monogenic, indeed the virus required a step-by-step selection for virulence, first towards major resistance genes, then towards the QTL and major gene combinations [80,81]. Brought back to our study case, as a combination of resistance QTL is efficient against a fungal strain, the adaptation to one of the QTL will not render overall resistance void. This is illustrated by the strain specificities of the identified QTL; i.e., though a strain has adapted to a specific QTL, this same QTL remains effective against the other strain. Qstb-renan-1D was detected only with fungal strain I05, while Qstb-renan$5 D$ was only detected with fungal strain I07. Finally, Qstb-renan-7B did not discriminate between the strains. We therefore have different QTL combinations that are efficient against different fungal strains. This entails no specific strain selection as the selection pressure is in a way diluted between strains [76]. It has been previously suggested that either pyramiding broad-spectrum factors or using host genotypes carrying narrow-spectrum resistance QTL could minimize resistance erosion [82] and that combining specific QTL that can complement each other can slow selection of one particular pathogen strain [82] increasing the durability of quantitative resistance.

Though there are many arguments in favour of durable quantitative resistance, it is not necessarily the panacea. There are pathosystems where quantitative resistance has been overcome through pathogen adaptation. In the case of the aforementioned pepper/Potato virus $Y$, quantitative resistance alone was not sufficient to halt adaptation, emphasis was put on the possibility of implementing cultivar mixtures [83]. In the apple/Venturia inaequalis pathosystem use of broad-spectrum quantitative resistance was shown to present a risk of encouraging the emergence of generalist pathogen populations [84]. In the wheat/Puccinia recondita f. sp. tritici pathosystem, it has been shown that partial resistance can be eroded when natural selection is high [85]. Another example is the grapevine/Plasmopara viticola interaction, where partial host resistance rapidly selected for pathogens with higher virulence [86]. These different examples show that though quantitative resistance is considered to be durable, its use does need to be carefully thought through, with emphasis on diversification of resistance mechanisms, a combination of both broad spectrum and narrow spectrum resistance QTL, and the implementation of certain cultural practices, such as cultivar mixtures for example.

\subsection{Molecular Mechanisms Underlying Resistance QTL}

Identifying the genes underlying the detected QTL would provide more insight into quantitative resistance and reveal the variety of mechanisms potentially involved in resistance to Z. tritici. Moreover, the use in breeding of resistance factors with distinct mechanisms could yet more complexify any pathogen adaptation $[76,87]$.

For the three QTL detected in this study, the parent carrying the resistance allele is the cultivar Renan. Renan carries known resistance genes to a number of diseases, including rust resistance genes $Y r 17, L r 37$, and Sr38, all originating from a chromosomal introgression from Aegilops ventricosa on wheat chromosome 2AS [88-90], eyespot resistance gene Pch1 on chromosome 7D [91,92], and powdery mildew resistance gene $P m 4 b$ on chromosome 2AL $[91,93]$. None of these known resistances to other diseases colocalize with the three QTL detected in this study. Qstb-renan-7B was detected on the long arm of chromosome 7B. Two Stb genes are found on chromosome 7B [15], these are Stb13 and Stb8. Qstb-renan-7B could colocalize with $S t b 8$ as it was detected towards the telomeric region of the long arm of chromosome $7 \mathrm{~B}$ although this should be validated by using microsatellite markers Xgwm146 and Xgwm577 [94]. Chromosome 1D carries two known Stb genes, these are Stb10 and Stb19 [15,16]. Stb10 is however not found close to the telomere as Qstb-renan-1D is, but rather near the centromere [95]. This QTL does however colocalize with Stb19 [16]. 
The twenty-seven candidate genes in the Stb19 region identified by Yang et al. (2018) with known $R$ gene families are included in the Qstb-renan-1D confidence interval [16]. Nine of these are in our NB-LRR type gene list (Table 6) and four of these BST_chr1D_nlr_13, BST_chr1D_nlr_113,BST_pseudo_chr1D_nlr_112, and BST_chr1D_nlr_14 had expression in the case of a Z. tritici infection (Figure 5). Therefore, Qstb-renan-1D could be an allele at $S t b 19$ although this remains to be validated through an allelism test between cultivars Renan and Lorikeet, the cultivar from which Stb19 was identified [16]. Chromosome 5D does not carry any known Stb genes although STB resistance QTL have been previously identified on the short arm of the chromosome. Bearing in mind that the Qstb-renan-5D confidence interval overlaps both the short and long arm, we can therefore not exclude the possibility that it colocalizes with previously identified QTL [18]. Qstb-renan-5D explained up to $36 \%$ of phenotypic variation and is located in a region where no $S t b$ gene has been mapped before. As previously discussed, the percentage of explained phenotypic variation cannot be considered as a criterion for the designation of a new Stb gene, because this percentage will strongly vary depending on the combination of effective resistances against a particular strain [24]. We therefore propose to designate this locus Stb20q in accordance with the $S t b$ nomenclature adding a ' $\mathrm{q}$ ' to indicate the quantitative nature of this locus despite its strong effect on resistance.

The three QTL detected here span overall quite a large interval on the genetic map and contain large numbers of genes, it is therefore impossible to consider studying all of these one by one. It is also possible that the gene or genes underlying the QTL are not present in Chinese Spring, it could therefore be interesting to look at other cultivar annotations. Renan in particular would be pertinent and the data will be available soon (F. Choulet, personal communication). The next best option would be to prune the list of genes to look into. Here, we chose to look into WAK, NB-LRR type and kinase domain carrying genes present in the QTL regions as these are seemingly the most likely gene families involved in quantitative disease resistance $[6,7,10,14]$ in the context of a potential gene-for-gene interaction $[23,24,96]$, a hypothesis we are encouraged to support by the strain specificities of the identified QTL. We are able to identify a short-list of genes in these gene families which could explain the detected QTL based on expression data, however, it would be interesting to test these further in the I05/Renan or I07/Renan interactions as the RNAseq data we have available was acquired from Riband inoculated with IPO323 [58]. So far, our results do not exclude that the genes underlying the detected resistance QTL could be based on similar mechanisms as known major $R$ genes. However, other as yet unexplored possibilities cannot be ignored, such as those suggested by Poland et al. [87] who proposed a variety of possibilities, including host plant development or morphology regulating genes, mutations in basal defence genes, detoxification mechanisms, defence signal transduction or partially altered weaker forms of $R$ genes. Their last suggestion was that the genes underlying resistance QTL could be a unique set of previously unidentified genes.

\section{Conclusions}

This study showed that the resistance in Renan to STB is quantitative and polygenic. In particular, it showed that Renan has a resistance QTL with a small effect, which colocalizes with Stb19 and a QTL with a strong effect on chromosome 5D, which was designated as Stb20q. For breeding, it could be interesting to introgress these regions from Renan into wheat cultivars as they would, in theory, be able to hold up resistance after pyramided major resistance genes are overcome, or even limit the erosion of major resistance genes [76]. Nevertheless, the QTL were detected with data generated in controlled conditions and at seedling stage, they should be validated in field conditions before any possible implementation in breeding programs. It seems the next step would be to fine-map the QTL intervals, as this would give us a better idea as to which of the identified candidate genes, if any, are responsible for the resistance QTL. Furthermore, we are currently investigating pathogenicity QTL in our strains of interest I05 and I07, in order to evidence potential 
interactions between known resistance QTL in Renan and fungal QTL, with the aim of deciphering the mechanisms of minor gene-for-minor gene interactions.

Supplementary Materials: The following are available online at https:/ / www.mdpi.com/article/ 10.3390/genes13010100/s1, Figure S1: Histograms representing the phenotypic data distribution for the 2017 datasets, Figure S2: Histograms representing the phenotypic data distribution for the 2018 datasets, Figure S3: Comparison between the RxCS genetic map and the wheat genetic map built by Rimbert et al. (2018) [65], Figure S4: Comparison between the RxCS genetic map and the RxCS genetic map built by Wang et al. (2014) [52], Figure S5: Representations of the RxCS genetic map. Table S1: Complete map, Table S2: Complete linkage analysis results.

Author Contributions: T.C.M. and R.V. conceived the experiments and edited the manuscript. C.L.-P. analysed the data and wrote the manuscript. S.B.K. conducted preliminary experiments that were required to select the most relevant plant and pathogen populations for this study. M.C., C.B. and S.G. collected the phenotypic data sets and carried out the first QTL analyses. P.S. participated in building the genetic linkage map and edited the manuscript. All authors have read and agreed to the published version of the manuscript.

Funding: The Camilla Langlands-Perry was funded by ARVALIS Institut du Végétal and the National Association for Research and Technology (CIFRE 2019/0608). This work was further supported by the French National Research Agency in the framework of the Investments for the Future (BREEDWHEAT: ANR-10-BTBR-03), by the EU Seventh Framework Programme (WHEALBI: FP7-613556) and by the French Fund to support Plant Breeding (FSOV 2016 W MABRUNE). INRAE BIOGER benefits from the support of Saclay Plant Sciences-SPS (ANR-17-EUR-0007).

Data Availability Statement: The ultra-dense genetic map built from the population Renan x Chinese Spring and used to map resistance QTL is provided as a supplementary data file.

Acknowledgments: We thank Etienne Paux and Cyrille Saintenac (INRAE GDEC) for their advice with the molecular markers and genome analyses. We also thank Delphine Hourcade (ARVALIS Institut du Végétal) for her critical follow-up of the project. We are grateful to Martin Willigsecker and Beatrice Beauzoone (INRAE BIOGER) for assistance in conducting the disease tests under controlled conditions.

Conflicts of Interest: The authors declare no conflict of interest.

\section{References}

1. Eyal, Z.; Scharen, A.L.; Prescott, J.M.; van Ginkel, M. The Septoria Diseases of Wheat: Concepts and Methods of Disease Management; CIMMYT: México-Veracruz, Mexico, 1987; 52p, ISBN 978-968-6127-06-5.

2. Fones, H.; Gurr, S. The impact of Septoria tritici Blotch disease on wheat: An EU perspective. Fungal Genet. Biol. 2015, 79, 3-7. [CrossRef]

3. O'Driscoll, A.; Kildea, S.; Doohan, F.; Spink, J.; Mullins, E. The wheat-Septoria conflict: A new front opening up? Trends Plant Sci. 2014, 19, 602-610. [CrossRef] [PubMed]

4. Niks, R.E.; Qi, X.; Marcel, T.C. Quantitative Resistance to Biotrophic Filamentous Plant Pathogens: Concepts, Misconceptions, and Mechanisms. Annu. Rev. Phytopathol. 2015, 53, 445-470. [CrossRef] [PubMed]

5. Dmochowska-Boguta, M.; Kloc, Y.; Zielezinski, A.; Werecki, P.; Nadolska-Orczyk, A.; Karlowski, W.M.; Orczyk, W. TaWAK6 encoding wall-associated kinase is involved in wheat resistance to leaf rust similar to adult plant resistance. PLoS ONE 2020, 15, e0227713. [CrossRef] [PubMed]

6. French, E.; Kim, B.-S.; Iyer-Pascuzzi, A.S. Mechanisms of quantitative disease resistance in plants. Semin. Cell Dev. Biol. 2016, 56, 201-208. [CrossRef] [PubMed]

7. Fu, D.; Uauy, C.; Distelfeld, A.; Blechl, A.; Epstein, L.; Chen, X.; Sela, H.; Fahima, T.; Dubcovsky, J. A Kinase-START Gene Confers Temperature-Dependent Resistance to Wheat Stripe Rust. Science 2009, 323, 1357-1360. [CrossRef]

8. Fukuoka, S.; Okuno, K. QTL analysis and mapping of pi21, a recessive gene for field resistance to rice blast in Japanese upland rice. Theor. Appl. Genet. 2001, 103, 185-190. [CrossRef]

9. Fukuoka, S.; Saka, N.; Koga, H.; Ono, K.; Shimizu, T.; Ebana, K.; Hayashi, N.; Takahashi, A.; Hirochika, H.; Okuno, K.; et al. Loss of Function of a Proline-Containing Protein Confers Durable Disease Resistance in Rice. Science 2009, 325, 998-1001. [CrossRef]

10. Gadaleta, A.; Colasuonno, P.; Giove, S.L.; Blanco, A.; Giancaspro, A. Map-based cloning of QFhb.mgb-2A identifies a WAK2 gene responsible for Fusarium Head Blight resistance in wheat. Sci. Rep. 2019, 9, 6929. [CrossRef]

11. Jiang, G.; Liu, D.; Yin, D.; Zhou, Z.; Shi, Y.; Li, C.; Zhu, L.; Zhai, W. A Rice NBS-ARC Gene Conferring Quantitative Resistance to Bacterial Blight Is Regulated by a Pathogen Effector-Inducible miRNA. Mol. Plant 2020, 13, 1752-1767. [CrossRef] 
12. Krattinger, S.G.; Lagudah, E.S.; Spielmeyer, W.; Singh, R.P.; Huerta-Espino, J.; McFadden, H.; Bossolini, E.; Selter, L.L.; Keller, B. A Putative ABC Transporter Confers Durable Resistance to Multiple Fungal Pathogens in Wheat. Science 2009, 323, $1360-1363$. [CrossRef]

13. Manosalva, P.M.; Davidson, R.M.; Liu, B.; Zhu, X.; Hulbert, S.H.; Leung, H.; Leach, J.E. A Germin-Like Protein Gene Family Functions as a Complex Quantitative Trait Locus Conferring Broad-Spectrum Disease Resistance in Rice. Plant Physiol. 2009, 149, 286-296. [CrossRef] [PubMed]

14. Wang, Y.; Subedi, S.; De Vries, H.; Doornenbal, P.; Vels, A.; Hensel, G.; Kumlehn, J.; Johnston, P.A.; Qi, X.; Blilou, I.; et al. Orthologous receptor kinases quantitatively affect the host status of barley to leaf rust fungi. Nat. Plants 2019, 5, 1129-1135. [CrossRef] [PubMed]

15. Brown, J.K.; Chartrain, L.; Lasserre-Zuber, P.; Saintenac, C. Genetics of resistance to Zymoseptoria tritici and applications to wheat breeding. Fungal Genet. Biol. 2015, 79, 33-41. [CrossRef] [PubMed]

16. Yang, N.; McDonald, M.C.; Solomon, P.S.; Milgate, A.W. Genetic mapping of Stb19, a new resistance gene to Zymoseptoria tritici in wheat. Theor. Appl. Genet. 2018, 131, 2765-2773. [CrossRef]

17. Vagndorf, N.; Nielsen, N.H.; Edriss, V.; Andersen, J.R.; Orabi, J.; Jørgensen, L.N.; Jahoor, A. Genomewide association study reveals novel quantitative trait loci associated with resistance towards Septoria tritici blotch in North European winter wheat. Plant Breed. 2017, 136, 474-482. [CrossRef]

18. Gerard, G.S.; Börner, A.; Lohwasser, U.; Simon, M.R. Genome-wide association mapping of genetic factors controlling Septoria tritici blotch resistance and their associations with plant height and heading date in wheat. Euphytica 2017, 213, 27. [CrossRef]

19. Karlstedt, F.; Kopahnke, D.; Perovic, D.; Jacobi, A.; Pillen, K.; Ordon, F. Mapping of quantitative trait loci (QTL) for resistance against Zymoseptoria tritici in the winter spelt wheat accession HTRI1410 (Triticum aestivum subsp. spelta). Euphytica 2019, 215, 108. [CrossRef]

20. Odilbekov, F.; He, X.; Armoniené, R.; Saripella, G.V.; Henriksson, T.; Singh, P.K.; Chawade, A. QTL Mapping and Transcriptome Analysis to Identify Differentially Expressed Genes Induced by Septoria Tritici Blotch Disease of Wheat. Agronomy 2019, 9, 510. [CrossRef]

21. Yates, S.; Mikaberidze, A.; Krattinger, S.G.; Abrouk, M.; Hund, A.; Yu, K.; Studer, B.; Fouche, S.; Meile, L.; Pereira, D.; et al. Precision Phenotyping Reveals Novel Loci for Quantitative Resistance to Septoria Tritici Blotch. Plant Phenomics 2019, 2019, 3285904. [CrossRef] [PubMed]

22. Riaz, A.; KockAppelgren, P.; Hehir, J.G.; Kang, J.; Meade, F.; Cockram, J.; Milbourne, D.; Spink, J.; Mullins, E.; Byrne, S. Genetic Analysis Using a Multi-Parent Wheat Population Identifies Novel Sources of Septoria Tritici Blotch Resistance. Genes 2020, $11,887$. [CrossRef] [PubMed]

23. Saintenac, C.; Lee, W.-S.; Cambon, F.; Rudd, J.J.; King, R.C.; Marande, W.; Powers, S.J.; Bergès, H.; Phillips, A.L.; Uauy, C.; et al. Wheat receptor-kinase-like protein Stb6 controls gene-for-gene resistance to fungal pathogen Zymoseptoria tritici. Nat. Genet. 2018, 50, 368-374. [CrossRef] [PubMed]

24. Saintenac, C.; Cambon, F.; Aouini, L.; Verstappen, E.; Ghaffary, S.M.T.; Poucet, T.; Marande, W.; Berges, H.; Xu, S.; Jaouannet, M.; et al. A wheat cysteine-rich receptor-like kinase confers broad-spectrum resistance against Septoria tritici blotch. Nat. Commun. 2021, 12, 433. [CrossRef]

25. Zhong, Z.; Marcel, T.C.; Hartmann, F.E.; Ma, X.; Plissonneau, C.; Zala, M.; Ducasse, A.; Confais, J.; Compain, J.; Lapalu, N.; et al. A small secreted protein in Zymoseptoria tritici is responsible for avirulence on wheat cultivars carrying the Stb6 resistance gene. New Phytol. 2017, 214, 619-631. [CrossRef] [PubMed]

26. Doré, C.; Varoquaux, F. Histoire et Amélioration de Cinquante Plantes Cultivées; Editions Quae: Versailles, France, 2006; 812p, ISBN 2-7380-1215-9.

27. Doussinault, G.; Pavoine, M.-T.; Jaudeau, B.; Jahier, J. Évolution de la Variabilité Génétique chez le Blé. Doss. Environ. INRA 2001, 21,91-104.

28. Hanzalova, A.; Dumalasova, V.; Sumikova, T.; Bartos, P. Rust Resistance of the French Wheat Cultivar Renan. Czech J. Genet. Plant Breed 2007, 43, 53-60. [CrossRef]

29. Dedryver, F.; Paillard, S.; Mallard, S.; Robert, O.; Trottet, M.; Nègre, S.; Verplancke, G.; Jahier, J. Characterization of Genetic Components Involved in Durable Resistance to Stripe Rust in the Bread Wheat 'Renan'. Phytopathology 2009, 99, 968-973. [CrossRef]

30. Rolland, B.; Fontaine, L.; Mailliard, A.; Gardet, O.; Heumez, E.; Walczak, P.; Le Campion, A.; Oury, F.-X. From selection to cultivation with the support of all stakeholders: The first registration in France of two winter bread wheat varieties after value for cultivation and use evaluation in organic farming systems. Org. Agric. 2017, 7, 73-81. [CrossRef]

31. Brenchley, R.; Spannagl, M.; Pfeifer, M.; Barker, G.L.A.; D'Amore, R.; Allen, A.M.; McKenzie, N.; Kramer, M.; Kerhornou, A.; Bolser, D.; et al. Analysis of the bread wheat genome using whole-genome shotgun sequencing. Nature 2012, 491, 705-710. [CrossRef] [PubMed]

32. The International Wheat Genome Sequencing Consortium (IWGSC); Appels, R.; Eversole, K.; Feuillet, C.; Keller, B.; Rogers, J.; Stein, N.; Pozniak, C.J.; Choulet, F.; Distelfeld, A.; et al. Shifting the limits in wheat research and breeding using a fully annotated reference genome. Science 2018, 361, eaar7191. [CrossRef] 
33. Zhu, T.; Wang, L.; Rimbert, H.; Rodriguez, J.C.; Deal, K.R.; De Oliveira, R.; Choulet, F.; Keeble-Gagnère, G.; Tibbits, J.; Rogers, J.; et al. Optical maps refine the bread wheat Triticum aestivum cv. Chinese Spring genome assembly. Plant J. 2021, 107, 303-314. [CrossRef]

34. Uauy, C. Wheat genomics comes of age. Curr. Opin. Plant Biol. 2017, 36, 142-148. [CrossRef]

35. Sears, E.R.; Miller, T.E. The History of Chinese Spring Wheat. Cereal Res. Commun. 1985, 13, 261-263.

36. Qi, X.; Jiang, G.; Chen, W.; Niks, R.E.; Stam, P.; Lindhout, P. Isolate-specific QTLs for partial resistance to Puccinia hordei in barley. Theor. Appl. Genet. 1999, 99, 877-884. [CrossRef]

37. González, A.M.; Marcel, T.C.; Niks, R.E. Evidence for a Minor Gene-for-Minor Gene Interaction Explaining Nonhypersensitive Polygenic Partial Disease Resistance. Phytopathology 2012, 102, 1086-1093. [CrossRef] [PubMed]

38. Arru, L.; Francia, E.; Pecchioni, N. Isolate-specific QTLs of resistance to leaf stripe (Pyrenophora graminea) in the 'Steptoe' $\times$ 'Morex' spring barley cross. Theor. Appl. Genet. 2003, 106, 668-675. [CrossRef] [PubMed]

39. Leonards-Schippers, C.; Gieffers, W.; Schäfer-Pregl, R.; Ritter, E.; Knapp, S.J.; Salamini, F.; Gebhardt, C. Quantitative resistance to Phytophthora infestans in potato: A case study for QTL mapping in an allogamous plant species. Genetics 1994, 137, 67-77. [CrossRef] [PubMed]

40. Caranta, C.; Lefebvre, V.; Palloix, A. Polygenic Resistance of Pepper to Potyviruses Consists of a Combination of Isolate-Specific and Broad-Spectrum Quantitative Trait Loci. Mol. Plant-Microbe Interact. 1997, 10, 872-878. [CrossRef]

41. Shaw, M.W. Interacting effects of interrupted humid periods and light on infection of wheat leaves by Mycosphaerella graminicola (Septoria tritici). Plant Pathol. 1991, 40, 595-607. [CrossRef]

42. Boixel, A.-L.; Gélisse, S.; Marcel, T.C.; Suffert, F. Differential Tolerance to Changes in Moisture Regime during Early Infection Stages in the Fungal Pathogen Zymoseptoria Tritici. bioRxiv 2019, 867572. [CrossRef]

43. Kema, G.H.J.; Yu, D.; Rijkenberg, F.H.J.; Shaw, M.W.; Baayen, R.P. Histology of the Pathogenesis of Mycosphaerella Graminicola in Wheat. Phytopathology 1996, 86, 777-786. [CrossRef]

44. Ouaja, M.; Aouini, L.; Bahri, B.; Ferjaoui, S.; Medini, M.; Marcel, T.C.; Hamza, S. Identification of valuable sources of resistance to Zymoseptoria tritici in the Tunisian durum wheat landraces. Eur. J. Plant Pathol. 2020, 156, 647-661. [CrossRef]

45. Stewart, E.L.; McDonald, B.A. Measuring Quantitative Virulence in the Wheat Pathogen Zymoseptoria tritici Using HighThroughput Automated Image Analysis. Phytopathology 2014, 104, 985-992. [CrossRef] [PubMed]

46. Stewart, E.L.; Hagerty, C.H.; Mikaberidze, A.; Mundt, C.C.; Zhong, Z.; McDonald, B.A. An Improved Method for Measuring Quantitative Resistance to the Wheat Pathogen Zymoseptoria tritici Using High-Throughput Automated Image Analysis. Phytopathology 2016, 106, 782-788. [CrossRef]

47. Schneider, C.A.; Rasband, W.S.; Eliceiri, K.W. NIH Image to ImageJ: 25 Years of image analysis. Nat. Methods 2012, 9, $671-675$. [CrossRef]

48. Palmer, C.-L.; Skinner, W. Mycosphaerella graminicola: Latent infection, crop devastation and genomics. Mol. Plant Pathol. 2002, 3, 63-70. [CrossRef]

49. R Core Team. R: A Language and Environment for Statistical Computing; R Foundation for Statistical Computing: Vienne, Austria, 2019.

50. Danguy des Déserts, A.; Bouchet, S.; Sourdille, P.; Servin, B. Evolution of recombination landscapes in diverging populations of bread wheat. Genome Biol. Evol. 2021, 13, evab152. [CrossRef]

51. Kitt, J.; Danguy des Déserts, A.; Bouchet, S.; Servin, B.; Rimbert, H.; De Oliveira, R.; Choulet, F.; Balfourier, F.; Sourdille, P.; Paux, E. Genotyping of 4506 Bread Wheat Accessions with the TaBW410K SNP Array. Zenodo 2021. [CrossRef]

52. Wang, S.; Wong, D.; Forrest, K.; Allen, A.; Chao, S.; Huang, B.E.; Maccaferri, M.; Salvi, S.; Milner, S.G.; Cattivelli, L.; et al. Characterization of polyploid wheat genomic diversity using a high-density 90000 single nucleotide polymorphism array. Plant Biotechnol. J. 2014, 12, 787-796. [CrossRef]

53. Ronin, Y.I.; Mester, D.I.; Minkov, D.G.; Akhunov, E.; Korol, A.B. Building Ultra-High-Density Linkage Maps Based on Efficient Filtering of Trustable Markers. Genetics 2017, 206, 1285-1295. [CrossRef]

54. Kosambi, D.D. The Estimation of Map Distances from Recombination Values. In D.D. Kosambi: Selected Works in Mathematics and Statistics; Ramaswamy, R., Ed.; Springer India: New Delhi, India, 2016; pp. 125-130. ISBN 978-81-322-3676-4.

55. Voorrips, R.E. MapChart: Software for the Graphical Presentation of Linkage Maps and QTLs. J. Hered. 2002, 93, 77-78. [CrossRef]

56. Broman, K.W.; Wu, H.; Sen, Ś.; Churchill, G.A. R/qtl: QTL mapping in experimental crosses. Bioinformatics 2003, 19, 889-890. [CrossRef] [PubMed]

57. Borrill, P.; Ramirez-Gonzalez, R.; Uauy, C. expVIP: A Customizable RNA-seq Data Analysis and Visualization Platform. Plant Physiol. 2016, 170, 2172-2186. [CrossRef]

58. Ramírez-González, R.H.; Borrill, P.; Lang, D.; Harrington, S.A.; Brinton, J.; Venturini, L.; Davey, M.; Jacobs, J.; van Ex, F.; Pasha, A.; et al. The transcriptional landscape of polyploid wheat. Science 2018, 361, eaar6089. [CrossRef]

59. Rudd, J.J.; Kanyuka, K.; Hassani-Pak, K.; Derbyshire, M.; Andongabo, A.; Devonshire, J.; Lysenko, A.; Saqi, M.; Desai, N.M.; Powers, S.J.; et al. Transcriptome and Metabolite Profiling of the Infection Cycle of Zymoseptoria tritici on Wheat Reveals a Biphasic Interaction with Plant Immunity Involving Differential Pathogen Chromosomal Contributions and a Variation on the Hemibiotrophic Lifestyle Definition. Plant Physiol. 2015, 167, 1158-1185. [CrossRef] [PubMed]

60. Chartrain, L.; Brading, P.A.; Brown, J.K.M. Presence of the Stb6 gene for resistance to septoria tritici blotch (Mycosphaerella graminicola) in cultivars used in wheat-breeding programmes worldwide. Plant Pathol. 2005, 54, 134-143. [CrossRef] 
61. Kourelis, J.; Van Der Hoorn, R.A.L. Defended to the Nines: 25 Years of Resistance Gene Cloning Identifies Nine Mechanisms for R Protein Function. Plant Cell 2018, 30, 285-299. [CrossRef]

62. Steinberg, G. Cell biology of Zymoseptoria tritici: Pathogen cell organization and wheat infection. Fungal Genet. Biol. 2015, 79, 17-23. [CrossRef]

63. Badaeva, E.D.; Dedkova, O.S.; Gay, G.; Pukhalskyi, V.A.; Zelenin, A.V.; Bernard, S. Chromosomal rearrangements in wheat: Their types and distribution. Genome 2007, 50, 907-926. [CrossRef] [PubMed]

64. Broderick, J.B. Coenzymes and Cofactors. In eLS; American Cancer Society: Atlanta, GA, USA, 2001; ISBN 978-0-470-01590-2.

65. Rimbert, H.; Darrier, B.; Navarro, J.; Kitt, J.; Choulet, F.; Leveugle, M.; Duarte, J.; Rivière, N.; Eversole, K.; Le Gouis, J.; et al. High throughput SNP discovery and genotyping in hexaploid wheat. PLoS ONE 2018, 13, e0186329. [CrossRef]

66. Wen, W.; He, Z.; Gao, F.; Liu, J.; Jin, H.; Zhai, S.; Qu, Y.; Xia, X. A High-Density Consensus Map of Common Wheat Integrating Four Mapping Populations Scanned by the 90K SNP Array. Front. Plant Sci. 2017, 8, 1389. [CrossRef] [PubMed]

67. Hussain, W.; Baenziger, P.S.; Belamkar, V.; Guttieri, M.J.; Venegas, J.P.; Easterly, A.; Sallam, A.; Poland, J. Genotyping-bySequencing Derived High-Density Linkage Map and its Application to QTL Mapping of Flag Leaf Traits in Bread Wheat. Sci. Rep. 2017, 7, 16394. [CrossRef]

68. Ladejobi, O.; Mackay, I.J.; Poland, J.; Praud, S.; Hibberd, J.M.; Bentley, A.R. Reference Genome Anchoring of High-Density Markers for Association Mapping and Genomic Prediction in European Winter Wheat. Front. Plant Sci. 2019, 10, 1278. [CrossRef] [PubMed]

69. Fagundes, W.C.; Haueisen, J.; Stukenbrock, E.H. Dissecting the Biology of the Fungal Wheat Pathogen Zymoseptoria tritici: A Laboratory Workflow. Curr. Protoc. Microbiol. 2020, 59, e128. [CrossRef]

70. Riaz, A.; Hickey, L.T. Rapid Phenotyping Adult Plant Resistance to Stem Rust in Wheat Grown under Controlled Conditions. In Wheat Rust Diseases: Methods and Protocols; Periyannan, S., Ed.; Methods in Molecular Biology; Springer: New York, NY, USA, 2017; pp. 183-196. ISBN 978-1-4939-7249-4.

71. Habig, M.; Quade, J.; Stukenbrock, E.H. Forward Genetics Approach Reveals Host Genotype-Dependent Importance of Accessory Chromosomes in the Fungal Wheat Pathogen Zymoseptoria tritici. MBio 2017, 8, e01919-17. [CrossRef] [PubMed]

72. Boixel, A.-L.; Delestre, G.; Legeay, J.; Chelle, M.; Suffert, F. Phenotyping Thermal Responses of Yeasts and Yeast-like Microorganisms at the Individual and Population Levels: Proof-of-Concept, Development and Application of an Experimental Framework to a Plant Pathogen. Microb. Ecol. 2019, 78, 42-56. [CrossRef]

73. Maupetit, A.; Larbat, R.; Pernaci, M.; Andrieux, A.; Guinet, C.; Boutigny, A.-L.; Fabre, B.; Frey, P.; Halkett, F. Defense Compounds Rather Than Nutrient Availability Shape Aggressiveness Trait Variation Along a Leaf Maturity Gradient in a Biotrophic Plant Pathogen. Front. Plant Sci. 2018, 9, 1396. [CrossRef]

74. Thomas, C.; Mabon, R.; Andrivon, D.; Val, F. The Effectiveness of Induced Defense Responses in a Susceptible Potato Genotype Depends on the Growth Rate of Phytophthora infestans. Mol. Plant-Microbe Interact. 2019, 32, 76-85. [CrossRef]

75. Dutt, A.; Andrivon, D.; Jumel, S.; Le Roy, G.; Baranger, A.; Leclerc, M.; Le May, C. Life history traits and trade-offs between two species of the ascochyta blight disease complex of pea. Plant Pathol. 2020, 69, 1108-1124. [CrossRef]

76. Pilet-Nayel, M.-L.; Moury, B.; Caffier, V.; Montarry, J.; Kerlan, M.-C.; Fournet, S.; Durel, C.-E.; Delourme, R. Quantitative Resistance to Plant Pathogens in Pyramiding Strategies for Durable Crop Protection. Front. Plant Sci. 2017, 8, 1838. [CrossRef]

77. Parlevliet, J.E. Durability of resistance against fungal, bacterial and viral pathogens; present situation. Euphytica 2002, 124, 147-156. [CrossRef]

78. Harrison, B.D. Virus variation in relation to resistance-breaking in plants. Euphytica 2002, 124, 181-192. [CrossRef]

79. Lindhout, P. The perspectives of polygenic resistance in breeding for durable disease resistance. Euphytica 2002, 124, 217-226. [CrossRef]

80. Palloix, A.; Ayme, V.; Moury, B. Durability of plant major resistance genes to pathogens depends on the genetic background, experimental evidence and consequences for breeding strategies. New Phytol. 2009, 183, 190-199. [CrossRef] [PubMed]

81. Quenouille, J.; Paulhiac, E.; Moury, B.; Palloix, A. Quantitative trait loci from the host genetic background modulate the durability of a resistance gene: A rational basis for sustainable resistance breeding in plants. Heredity 2014, 112, 579-587. [CrossRef]

82. Van, A.L.; Caffier, V.; Lasserre-Zuber, P.; Chauveau, A.; Brunel, D.; Le Cam, B.; Durel, C. Differential selection pressures exerted by host resistance quantitative trait loci on a pathogen population: A case study in an apple $\times$ Venturia inaequalis pathosystem. New Phytol. 2013, 197, 899-908. [CrossRef] [PubMed]

83. Montarry, J.; Cartier, E.; Jacquemond, M.; Palloix, A.; Moury, B. Virus adaptation to quantitative plant resistance: Erosion or breakdown? J. Evol. Biol. 2012, 25, 2242-2252. [CrossRef]

84. Caffier, V.; Lasserre-Zuber, P.; Giraud, M.; Lascostes, M.; Stievenard, R.; Lemarquand, A.; van de Weg, E.; Expert, P.; Denancé, C.; Didelot, F.; et al. Erosion of quantitative host resistance in the apple $\times$ Venturia inaequalis pathosystem. Infect. Genet. Evol. 2014, 27, 481-489. [CrossRef]

85. Lehman, J.S.; Shaner, G. Selection of Populations of Puccinia recondita f. sp. tritici for Shortened Latent Period on a Partially Resistant Wheat Cultivar. Phytopathology 1997, 87, 170-176. [CrossRef] [PubMed]

86. Delmotte, F.; Mestre, P.; Schneider, C.; Kassemeyer, H.-H.; Kozma, P.; Richart-Cervera, S.; Rouxel, M.; Delière, L. Rapid and multiregional adaptation to host partial resistance in a plant pathogenic oomycete: Evidence from European populations of Plasmopara viticola, the causal agent of grapevine downy mildew. Infect. Genet. Evol. 2014, 27, 500-508. [CrossRef] 
87. Poland, J.A.; Balint-Kurti, P.J.; Wisser, R.J.; Pratt, R.C.; Nelson, R.J. Shades of gray: The world of quantitative disease resistance. Trends Plant Sci. 2009, 14, 21-29. [CrossRef]

88. Seah, S.; Bariana, H.; Jahier, J.; Sivasithamparam, K.; Lagudah, E.S. The introgressed segment carrying rust resistance genes Yr17, Lr37 and Sr38 in wheat can be assayed by a cloned disease resistance gene-like sequence. Theor. Appl. Genet. 2001, 102, 600-605. [CrossRef]

89. Bartos, P.; Ovesná, J.; Hanzalová, A.; Chrpová, J.; Dumalasová, V.; Škorpík, M.; Šíp, V. Presence of a Translocation from Aegilops ventricosa in Wheat Cultivars Registered in the Czech Republic. Czech J. Genet. Plant Breed. 2011, 40, 31-35. [CrossRef]

90. Ambrozková, M.; Dedryver, F.; Dumalasová, V.; Hanzalová, A.; Bartos, P. Determination of the cluster of wheat rust resistance genes Yr17, Lr37, and Sr38 by a molecular marker. Plant Prot. Sci. 2002, 38, 41-45. [CrossRef]

91. Gallais, A. Blé Renan: Un OGM Ignoré Très Utilisé Par L'agriculture Biologique. Available online: https:/ / www.biotechnologiesvegetales.com/wp-content/uploads/2020/04/FicheInfo06-Ble-Renan-un-OGM-ignore-tres-utilise-par-l-agriculture-bio.pdf (accessed on 3 December 2021).

92. Pasquariello, M.; Ham, J.; Burt, C.; Jahier, J.; Paillard, S.; Uauy, C.; Nicholson, P. The eyespot resistance genes Pch1 and Pch2 of wheat are not homoeoloci. Theor. Appl. Genet. 2016, 130, 91-107. [CrossRef] [PubMed]

93. Wu, P.; Xie, J.; Hu, J.; Qiu, D.; Liu, Z.; Li, J.; Li, M.; Zhang, H.; Yang, L.; Liu, H.; et al. Development of Molecular Markers Linked to Powdery Mildew Resistance Gene P $m 4 b$ by Combining SNP Discovery from Transcriptome Sequencing Data with Bulked Segregant Analysis (BSR-Seq) in Wheat. Front. Plant Sci. 2018, 9, 95. [CrossRef] [PubMed]

94. Adhikari, T.B.; Anderson, J.M.; Goodwin, S.B. Identification and Molecular Mapping of a Gene in Wheat Conferring Resistance to Mycosphaerella graminicola. Phytopathology 2003, 93, 1158-1164. [CrossRef] [PubMed]

95. Chartrain, L.; Berry, S.T.; Brown, J.K.M. Resistance of Wheat Line Kavkaz-K4500 L.6.A.4 to Septoria Tritici Blotch Controlled by Isolate-Specific Resistance Genes. Phytopathology 2005, 95, 664-671. [CrossRef] [PubMed]

96. Faris, J.D.; Zhang, Z.; Lu, H.; Lu, S.; Reddy, L.; Cloutier, S.; Fellers, J.P.; Meinhardt, S.W.; Rasmussen, J.B.; Xu, S.S.; et al. A Unique Wheat Disease Resistance-like Gene Governs Effector-Triggered Susceptibility to Necrotrophic Pathogens. Proc. Natl. Acad. Sci. USA 2010, 107, 13544-13549. [CrossRef] [PubMed] 